\title{
Getting out of Debt: The Road to Recovery for Victim/Survivors of Family Violence
}

\author{
By Dr Liz Curran, \\ Associate Professor \\ Australian National University School of Legal Practice \\ Second Research and Evaluation Report - Phase Two, January 2020
}

On the Consumer Action Law Centre Project: 'Responding Effectively to Family Violence Dimensions of Debt and Credit through Secondary Consultations \& Training with Community Professionals. 


\section{ACKNOWLEDGEMENTS}

Consumer Action's Family Violence Project ', which is the subject of this Evaluation Report, was funded by the Community Legal Centre's Family Violence Assistance Grant, administered by the Department of Justice and Regulation.

Consumer Action and Dr Curran wish to thank all the wonderful input by the non-legal professionals who were participants in this research and evaluation.

Also, many thanks to the staff of Consumer Action especially: Anna Goodluck, Lisa Grealy, Jillian Williams, Sumeet Kaur, Katia Sanderson, Galit Aflalo, Param Dhillon and Katie Fraser.

C) Dr Liz Curran, ANU, 2020 


\section{Part A - Research Evaluation Context, Background Methodology and Approach}

The Consumer Action Law Centre's (Consumer Action) 'Responding Effectively to Family Violence Dimensions of Debt and Credit through Secondary Consultations \& Training with Community Professionals' Project ('the project') is funded by the Victorian Government as a response to the Royal Commission into Family Violence (RCIFV) $)^{i i}$ recommendations.

The contract between Consumer Action and the Victorian Government requires Consumer Action to provide an acquittal due on 7 January 2019. This Research and Evaluation Report will be annexed to this acquittal but will also be available publicly to shape and inform other service delivery models and policy development across government departments and across jurisdictions.

Dr Liz Curran, ANU School of Legal Practice was approached on 7 September 2017 to undertake the evaluation (on a pro bono basis). Baseline data was collected in October November in 2017 with the publication of a first phase report in December 2017. This is the second phase of the study with data collected October - end November 2019. Australian National University Human Ethics Approval for the whole project was undertaken through an expedited process and granted on 24 October 2017. Consumer Action also engaged Dr Curran to conduct a project 'check in' and report in December 2018 which will be referred to in this report and which fell within an ethics variation secured in September 2018.

As Dr Curran has been involved in this project evaluation since 2017 it has been an embedded evaluation. The baseline data collected in 2017 has been used to make comparisons as to the effectiveness and impact of the project over time, using the 'Collaborative measurement tool' that was developed by the author.iii

Consumer Action's strategic documentation notes that it is working to create a just marketplace where people have power and business plays fair. It operates legal advice and financial counselling services and delivers outreach and training to community workers in Victoria. This experience in direct service provision informs its policy and campaign work, at a national level, seeking changes to policy, laws and industry practice that make life easier for people experiencing vulnerability and disadvantage in Australia.

Consumer Action's lawyers provide information, advice, referrals and ongoing assistance over the phone and by email to people living in Victoria (via a 'consumer advice service') and provide representation services to some clients. This advice and casework help inform Consumer Action's policy and advocacy work to identify and address systemic issues. Consumer Action also provides legal secondary consultations ${ }^{i v}$ to community workers (via a phone and email 'worker advice service'), undertakes outreach to Koori communities across the state and runs a Koori helpline for Aboriginal clients.

\section{Author Background}

This research evaluation is conducted by Dr Liz Curran of the ANU School of Legal Practice. She holds a Doctorate in Juridical Science. Dr Curran (the author) was also 'Expert Adviser' to 
the Law Council of Australia's 'Justice Project'. She is accustomed to project management and project delivery.

The author's evidence-based research is around effective legal practice including multidisciplinary practice. This is where lawyers work collaboratively with community professionals to reach clients unlikely to gain legal help due to barriers. She has published research reports and evaluations $(2007,2011,2012,2013,2015,2016,2017,2018)$ on outcomes, quality and effectiveness, disadvantage and on 'Strategic Approaches to Problem Solving' (March 2013).

Between 2014 and end 2022, Liz is commissioned to conduct a number of research evaluations on Multi -Disciplinary practice (MDP) including Health Justice Partnerships (HJP) in Australia and is advising on similar projects in Canada and the UK. She is a Senior Fellow at Nottingham Trent University and Visiting Scholar (ongoing) at University of Portsmouth in the United Kingdom. The author has also previously evaluated family violence projects ${ }^{\vee}$ and is published in the area. ${ }^{\text {vi }}$ She is a member of the Australian Society of Evaluators and abides by its Code of Conduct in her evaluation work.

\section{Reasons for the Project}

The Report of the Royal Commission into Family Violence recognised that the family violence victim's financial security has impacts on their wellbeing, recovery and social determinants of health ${ }^{\text {vii. }}$ Many problems interact in relation to family violence related debt:

1. The considerable difficulties victims face in asserting and enforcing their financial rights alone;

2. A systemic failure by financial and utility service providers "to understand, identify and respond to economic abuse"; and

3. Inadequate legal and regulatory protections.

The impact of these problems is most significant in relation to joint debts and financial hardship. viii These issues were also identified elsewhere in other reports. ${ }^{\text {ix }}$

The Royal Commission found an urgent need to improve the capacity of industry and its employees in understanding, identifying and responding to economic abuse. It also recognised existing impediments for women experiencing family violence in finding help and being heard ${ }^{\mathrm{x}}$; and the need for clear and accessible laws, regulations and processes to enable victims to resolve ongoing financial complexities, and to achieve a clearer pathway towards financial security.

\section{About the Project}

Funding was provided by the Department of Justice and Regulation. The aims of this project are to

1. Continue existing Secondary Consultation services to financial counsellors, community lawyers and other family violence workers to ensure they have access to expert consumer credit and debt advice and assistance and thereby strengthen their ability 
to advocate for victims in relation to family violence-related debt;

2. Continue existing Outreach and Training services to financial counsellors, community lawyers and other family violence workers to improve their understanding of the ways in which credit and debt laws apply to family violence situations and thereby improve their capacity to identify their clients' credit and debt legal issues in family violence situations and provide timely and appropriate referrals;

3. To grow the empirical evidence base of family violence related consumer, credit and debt issues. This would then allow Consumer Action to undertake informed advocacy for reform to both laws and industry practices so that they are providing appropriate responses to family violence related debt.

The project aims to overcome barriers identified in previous studies ${ }^{x i}$ by providing a Secondary Consultation (SC) service ${ }^{x i i}$ integrated with Consumer Action's Training and Outreach program and to build Consumer Action's capacity for strategic advocacy. The project seeks to, work with trusted community professionals to whom people experiencing family violence are likely to turn and enable their credit \& debt legal issues to be addressed in a timely and effective way breaking down barriers that exist to seeking legal help. ${ }^{\text {iii }}$

Secondary consultations are defined as:

... where a lawyer offers a non-legal professional (such as a doctor, nurse, youth worker, social worker or financial counsellor) legal information or advice on legal processes for their client through the non-legal professional as an intermediary or assists the professional in their role (such as what happens at court, and how to give evidence or structure reports for a court to provide the required considerations), or on their professional and ethical obligations, or guides the non-legal professional through tricky situations involving their client or their work for clients. It is 'secondary' in that the legal information is provided to the professional intermediary who is already supporting a client and then this intermediary uses this information to assist their client or patient or the information is used to enable the professional to better support the client. $^{\text {xiv }}$

In this project only, the aggregated data collected by Consumer Action for SC has included in it 'clc lawyers'. The funding application by Consumer Action to the Department of Justice and Regulation included 'clc lawyers' in their definition of SC. The author notes that, SC sits in a broader research context where SC are designed to broaden service to non-legal professionals to better reach clients, not currently finding legal help. If clients are already seeing a clc or other lawyer, then this is not within the extant research context from which SC emerges and the literature on the rationale for SC. Namely, that if clients are already with a lawyer then they have reached the legal system and the identification of an issue as legal and obviates the barriers that SC are designed specifically to overcome. Normally the discourse around lawyer advice to other lawyers in this context would be referred to as the provision of 'generalist' and 'specialist' legal assistance where Consumer Action would be characterised as a 'specialist' legal service. The author's initial brief for the embedded evaluation in 2017 for 
gaining base line data and for this 2019 study was to focus on the impact of the service for non-legal professionals and reach to clients in debt and credit matters. The definition of SC by Consumer Action has made the author recalibrate some findings meaning comparisons with other studies has been less possible. However, the definition used in the in-depth interviews uses the universally accepted definition of SC and so the comparisons about reach and access to lawyers remains applicable.

The resources for the project include the provision of training, secondary consultation and the collection of empirical evidence by a lawyer with expertise in family violence issues related to consumer, credit and debt matters. This, it was hoped, would improve the nonlegal sector's capacity to 'issue spot' consumer credit \& debt law issues in family violence situations, increase appropriate referrals and assist non-legal professionals to achieve enhanced outcomes at an earlier stage for financial problems. At a number of training sessions there was sometimes a mix of lawyers and non-lawyers present (as reflected in the data below). Whilst not a specific aim of the project, a notable result of the project is that it enabled Consumer Action to build and strengthen relationships and engagement within the community sector.

\section{The Project Aims}

Family Violence is an area of high need. There is a great public interest in ameliorating its flow on impacts to victims and their families. This project seeks to do this by working with trusted professional intermediaries to whom victims are likely to turn in debt and credit matters. Finances play a significant part in recovery including, as this research reveals, finding much needed money to pay rent, school fees, utilities and for food. The statistics reflect that it is most likely that women will be the victims/survivors. People experiencing family violence are left with debts incurred by their former violent partners. As the case studies in this report highlight, people are sometimes left in great hardship with resultant stress and anxiety that can impact on their health and wellbeing and that of other family members.

Consumer Action's Secondary Consultation (SC) and Outreach and Training project aims to strengthen the capacity of the financial counselling and family violence support sectors to assist and respond to people dealing with family violence-related debt. Through expanding Consumer Action's empirical evidence base, the project enables Consumer Action to continue to advocate for improved system responses to how such matters are handled.

Building collaboration, respect and trust between services is critical to build capacity, confidence and responsiveness. ${ }^{\mathrm{x}}$ Partnerships with other service delivery agencies with the ability to offer 'one-stop shop' integrated services are critical to minimising delay and can ensure (if done well) holistic action. ${ }^{x v i}$ This is especially important given the complexities that arise due to the intersection of family law, consumer protections and debt recovery laws. By augmenting the capacity of community workers to understand, identify, respond and deal with the credit and debt issues arising out of family violence the project aims to ensure that through their work with community professionals, Consumer Action can ensure victims are made aware of their legal rights and how to enforce those rights as early as possible. 
Another aim of the project is to ensure Secondary Consultations and Training and Outreach services are tailored to the needs of the individual community professionals to ensure that the advice and assistance provided is practical and appropriate. Previous research has also shown that secondary consultation can also be an efficient form of 'on the job' training for busy professionals who are time poor.

In addition, the capacity to ensure that the causes of problems that need a policy response, often called 'systemic issues' are being addressed by the family violence credit and debt legal team and community professionals is being assessed in this evaluation. This is being assessed by examining the identification of concerning trends, involvement and engagement in policy forums to identify and find solutions and the impacts of such work. To this end one of the project aims is to improve industry policies and the laws that impact on family violence victims. These aims have been measured by the methodology discussed below, to see if the levels of effectiveness of the Consumer Action Law Centre's interventions and whether there are improvements that can or are occurring.

As Consumer Action receives funding from a range of sources in relation to its secondary consultation, outreach and training and strategic advocacy work, it is important to acknowledge that some of the impacts noted in this report may also be attributed to Consumer Action's use of its combined funding sources.

\section{The Project Research Evaluation}

The Department of Justice and Regulation in Victoria has funded Consumer Action for the service component of the project. The service has recently been refunded for a further two and half years, with funding to be managed by Victoria Legal Aid. In commissioning this and other reports, Consumer Action is keen to build an evidence base on the impacts of secondary consultations and what works well and why or why not and in what circumstances. ${ }^{\text {vii }}$ This is to inform future good practice and evidence informed service delivery and to enhance the responsiveness to families experiencing family violence. This evaluation goes beyond the Department of Justice and Regulation requirements and Key Performance Indicators (KPIS) for acquittal, to contribute and inform service delivery more broadly. The other reason includes the process of reflective practice within a model of constant service learning and improvement that Consumer Action adopts. Dr Curran's involvement is on a pro bono basis given there is no additional funding for evaluation.

\section{Methodology and Approach for the Research Evaluation}

Participatory action research has been described as a reflective process ${ }^{x v i i i}$ of progressive problem solving led by individuals working as part of a 'community of practice' to improve the way they address issues and solve problems (Dick 1999/2011). xix Using a participatory, action research approach means literature and research informed practice informs the project. Using multiple tools to gather data, this research evaluation enables themes emerging to be tested and verified across the tools over time due to it being an embedded evaluation from project start-up. 
Multiple tools such as in-depth interviews ${ }^{\mathrm{xx}}$ and aggregated training survey and service data ${ }^{\mathrm{xxi}}$ are used in this research evaluation. It is important to use multiple methods of data collection to reduce bias and test and verify results across the tools.

Proxies as measures/indicators of effectiveness and impact of the project are as follows (based on Dr Curran's previous work ${ }^{\mathrm{xxii}}$ ):

- Engagement - professionals, staff and organisations

- Capacity - professional, staff and organisations

- Collaboration - professional, staff and organisations

- Empowerment - professional, staff and organisations. This includes giving voice for improved advocacy for client / professional towards systemic change

As noted above Curran's Collaborative Measurement Tool adapted from the VicHealth Collaborative Tool has been used to benchmark against data collected since 2017 to gauge the breaking down of professional barriers and examine collaboration and interpersonal skill development over the life of the project.

The research component of the evaluation is to gauge the impact on confidence and capacity of community professionals using secondary consultation that is twinned/integrated with a training outreach model.

Qualitative \& Quantitative Data was collected. Dr Curran has written elsewhere about the dangers of interpreting aggregated data without having qualitative data to explain complexity and nuance. xxiii Although collection of qualitative data is time consuming and resource intensive, in areas as complex as family violence and the conduct of debt and credit and their impact on the outcomes and social determinants of health, qualitative data is important in gaining a complete picture and understanding what works or does not work and why and impact. ${ }^{\text {xiv }}$

\section{Qualitative Data}

The questionnaire for the in-depth interviews seeks to elicit responses to suggest whether community professionals are confident in using secondary consultations and in referring victims of family violence to Consumer Action. This includes the utility of information, advice and referrals from Consumer Action.

Indicators of effectiveness and impact on health and social outcomes include:

- Changes in professional practice

- Value of SC

- Engagement

- Capacity

- Confidence

- Collaboration

- Empowerment

- Reductions in client and professional stress and anxiety

- Enhanced decision making

- Increase in client hope 
- Responsiveness

- Reach to clients experiencing family violence who might otherwise not receive debt and credit support

- Self-care of staff in family violence work

- Professional and client capacity and confidence and good practice

- Issues and complexities for their clients experiencing family violence with debt and credit issues and responsiveness to these.

- Referral pathways between organisations

- Client stories from community professionals illustrating the range and impacts of family violence related credit and debt issues.

- Appropriateness and effectiveness of services and referrals

- Systemic collaboration and problem identification

The questionnaire for the in-depth interviews contains a blend of Qualitative \& Quantitative questions. The research was aggregated and all participants de-identified in line with ANU Ethics Approval requirements and the National Guidelines for Health and Medical Research. Another key endeavour through collecting and analysing the data is to examine what works, why or why not and in what circumstances.

\section{Quantitative Data}

\section{Aggregated Consumer Action Service Data}

Other research data collected was by a desktop examination with data collected by Consumer Action in response to a series of questions from the author. This occurred given the limited resources and time for the research evaluation. This data is extracted from the ActionStep and File Pro data base of Consumer Action. The author wanted to compare data to test the numbers of people who were engaging more with the service, after training.

If there was an increase in uptake of the service after training this would have indicated effectiveness of training. Unfortunately, despite attempts to extract this data, it was difficult due to the change-over in data systems to pull the data together across the different systems. Consumer Action is working on ways to extract such data moving forward to enable such a comparison.

The service's data on family violence work (involving clients with consumer, credit \& debt issues) about numbers of secondary consultation and training feedback has been aggregated and de-identified by Consumer Action before being handed to the author. This has been analysed and summarised in line with the ethics approval protocol.

This data from Consumer Action includes:

1. Data on number of cases where there has been assistance to community professionals. (Contracted KPI)

2. Data on numbers of assistance to community professionals. (Contracted KPI)

3. Data on numbers of assistance to community professionals outreach/training sessions. 
4. Data on the number and type of referrals relating to family violence matters both into and out of the organisation. (Contracted KPI)

5. Pre-evaluation and post-evaluation training surveys. These have been integrated with existing surveys administered by collaborating agencies to minimise work and have included a couple of questions about Consumer Action, for example the Women's Information and Referral Exchange (WIRE) incorporated Consumer Action training in its existing surveys. These agencies have collaborated on the training and outreach and have built pre-training assessments into the evaluation of the training. (Stakeholder feedback Contracted KPI)

6. Data on the number of secondary consultations undertaken by Consumer Action since the project was funded in comparison to base line data from 2017.

7. Involvement in systems reform for example, involvement in the Economic Abuse Reference Group. (Contracted KPI)

8. Impact of involvement in systems reform for example, involvement in the Economic Abuse Reference Group.

The data for this is reproduced below together with some brief analysis and comparison with the baseline data from 2017.

The author is advised, that the Evaluation of the Training and Outreach Services questions, cover the following:

- Community professionals can recognise key credit and debt legal issues experienced by their clients.

- Whether there is expanded availability to community professionals of expert credit \& debt legal advice and assistance resolving financial problems earlier

- Levels of improved sector capacity to 'issue spot' credit \& debt law issues in family violence situations and provide timely and appropriate referrals

- Levels of improved understanding of the nature and extent of family violence related debt-issues through collection of data.

- Evidence of unmet demand for expert legal advice and assistance in credit and debt problems arising out of family violence.

The author notes that as the survey for training is administered by Consumer Action and integrated into other agency surveys, she has had limited ability to ensure consistent administration of the questions and this is a challenge for Consumer Action as well. 
PART B - Data 1 December 2016 - 13 November 2019

\section{Quantitative Data}

\section{Background and Response Rate In-depth Interviews 2019}

In September 2019, the author wrote to eighty non-legal community professionals who had accessed the project, providing information about the research evaluation, the questionnaire and consent forms seeking voluntary participation in an in-depth interview, in line with ANU Human Ethics Approval.

As a result, ten non-legal community professionals responded and agreed to be interviewed. This was a response rate of $12.5 \%$. There is a generally accepted average $10-15 \%$ response rate for external surveys such as this one. Two participants however were unable to be interviewed due to leave arrangements of participants and difficulty coordinating interview times in the month of October 2019. The participating interviewees were then contacted by phone. In line with ethics approval they have been de-identified. This meant that eight community professionals were able to be interviewed for the research and evaluation project. This is an increase of two participants since the 2017 study. ${ }^{x x v}$

There was a mix of urban and regional community professionals and due to the short time frame all interviews were over the phone with detailed notes being taken on the questionnaire as to their responses. The question numbering is out sequence in the discussion below reflecting the categorisation of quantitative data and qualitative questions.

\section{Quantitative Data 2019 from In-depth Interviews}

A. Did you have any secondary consultations (SC) with the lawyer?

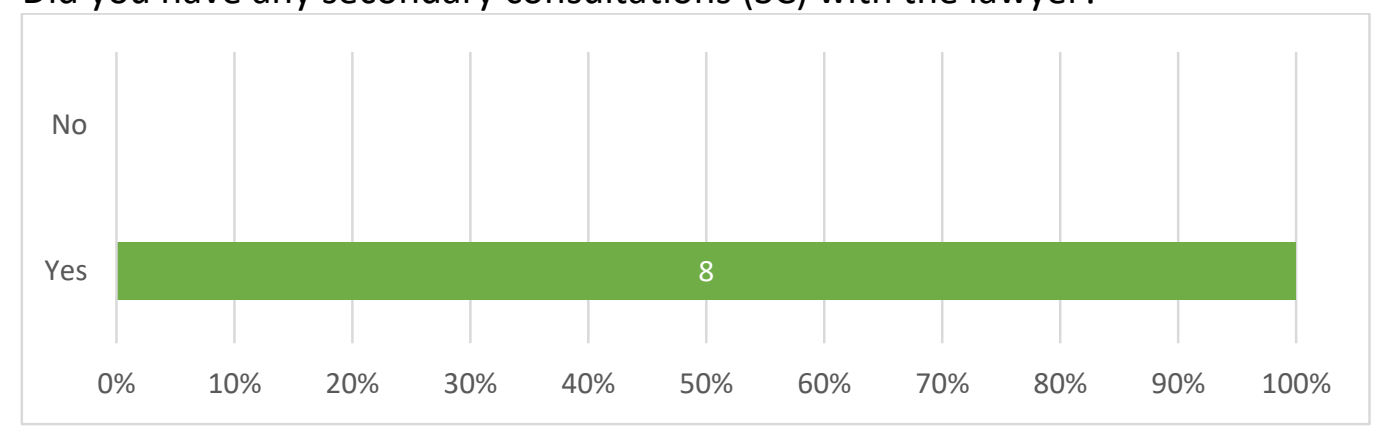


B. Do you use the SC information for more clients than you seek the initial advice for?

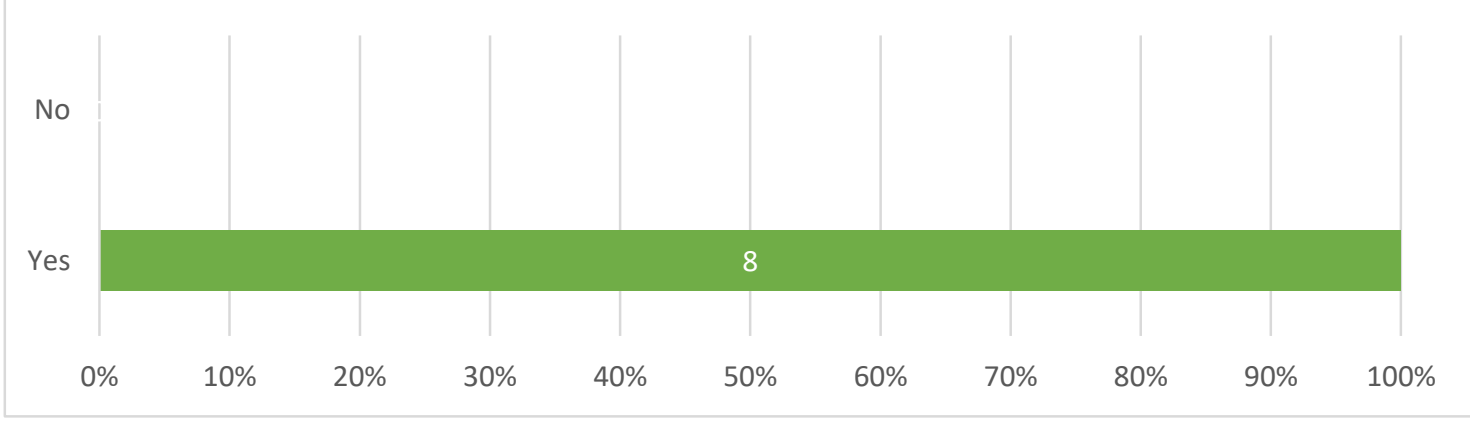

C. Do you think that providing SC to non-legal professionals is enabling more clients to be reached than would otherwise be the case without the SC?

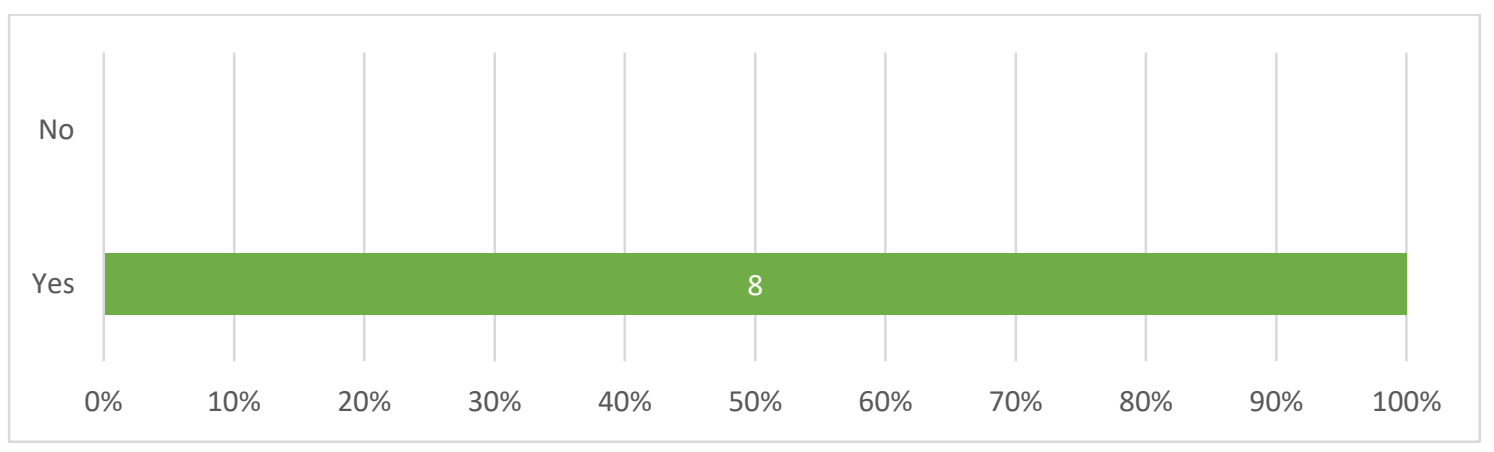

Question 1. If I were to make these statements in relation to the Project how would you respond?

A. I can confidently and positively refer

\begin{tabular}{|c|c|c|c|c|}
\hline Strongly Disagree & Disagree & Neutral & Agree & Strongly Agree \\
\hline $\mathbf{0}$ & $\mathbf{0}$ & $\mathbf{0}$ & $\mathbf{1}$ & $\mathbf{7}$ \\
\hline
\end{tabular}

B. The referral process to and from clearly understood

\begin{tabular}{|c|c|c|c|c|}
\hline Strongly Disagree & Disagree & Neutral & Agree & Strongly Agree \\
\hline $\mathbf{0}$ & $\mathbf{0}$ & $\mathbf{0}$ & $\mathbf{3}$ & $\mathbf{5}$ \\
\hline
\end{tabular}

C. There is a high level of mutual understanding and trust between you and Consumer Action Law Centre (Consumer Action

\begin{tabular}{|c|c|c|c|c|}
\hline Strongly Disagree & Disagree & Neutral & Agree & Strongly Agree \\
\hline $\mathbf{0}$ & $\mathbf{0}$ & $\mathbf{0}$ & $\mathbf{1}$ & $\mathbf{7}$ \\
\hline
\end{tabular}

D. Through the project I have gained an understanding of other professions ethics and boundaries 


\begin{tabular}{|c|c|c|c|c|}
\hline Strongly Disagree & Disagree & Neutral & Agree & Strongly Agree \\
\hline 0 & 0 & 1 & 5 & 2 \\
\hline
\end{tabular}

E. The staff involved in the Project (i.e. the lawyer) recognise and utilise the professional expertise of other staff.

\begin{tabular}{|c|c|c|c|c|}
\hline Strongly Disagree & Disagree & Neutral & Agree & Strongly Agree \\
\hline 0 & 1 & 1 & 2 & 4 \\
\hline
\end{tabular}

F. The lawyer/s are responsive to practitioner need.

\begin{tabular}{|c|c|c|c|c|}
\hline Strongly Disagree & Disagree & Neutral & Agree & Strongly Agree \\
\hline $\mathbf{0}$ & $\mathbf{1}$ & $\mathbf{0}$ & $\mathbf{3}$ & $\mathbf{4}$ \\
\hline
\end{tabular}

Comment: This data suggests that Consumer Action's referral process is effective.

There are high levels of trust that have developed over the life of the project with an increase in 'Strongly Agree' from the 2017 data collected in the early phase of the project.

Area for Improvement: There is some feedback (low in incidence) that there could be more respect for the expertise of other non-legal professionals and an increase in the utility of information provided and less use of legal jargon thus improving understandability and communication. It was suggested by one participant that this goes to induction of new staff and junior lawyers joining Consumer Action and the reality of the importance of digestible information for busy workers who are not lawyers and for clients who need to be fully informed and who are already overwhelmed.

G. I not only examine the individual client's problems but look to change the systemic causes of problems including the laws and how they are administered.

\begin{tabular}{|c|c|c|c|c|}
\hline Strongly Disagree & Disagree & Neutral & Agree & Strongly Agree \\
\hline $\mathbf{0}$ & $\mathbf{0}$ & $\mathbf{1}$ & $\mathbf{3}$ & $\mathbf{3}$ \\
\hline
\end{tabular}

Summarised from the Substantial Majority of Participant Reponses

Comment: Significantly more non-legal professionals were engaged in systemic policy than in 2017. Two participants wanted to know more about how they could be more involved. All participants reported that they would like to get more feedback on actions taken and impacts. This was similar to findings in 2017.

Improvement: Consumer Action could do more to improve its feedback loop to non-legal professionals who contribute to their policy work. The professionals commented that family 
violence work is draining and that such inclusion would be empowering as it would help them feel they were contributing to 'the bigger picture' as well.

H. There is huge value to me in assisting patients/clients' due to secondary consultations with the lawyer/s who give me legal advice both to support me assist the client and to guide me in my professional obligations in the context of the legal process and the laws.

\begin{tabular}{|c|c|c|c|c|}
\hline Strongly Disagree & Disagree & Neutral & Agree & Strongly Agree \\
\hline 0 & 0 & 0 & 1 & 7 \\
\hline
\end{tabular}

Comment: Consistently with other emerging research on SC, SC is seen to have huge value by all participants.

Question 14 Have you noticed any of the following for yourself as a professional since the involvement of the lawyer/s in the inter-disciplinary team of the project in any of the following areas in the case example provided today (see below):

A Stress.

\begin{tabular}{|c|c|c|}
\hline Been reduced & Stayed the same & Has increased \\
\hline 4 & 4 & 0 \\
\hline
\end{tabular}

B Resilience

\begin{tabular}{|c|c|c|}
\hline Been reduced & Stayed the same & Has increased \\
\hline 0 & 3 & 5 \\
\hline
\end{tabular}

\section{Anxiety}

\begin{tabular}{|c|c|c|}
\hline Been reduced & Stayed the same & Has increased \\
\hline 5 & 3 & 0 \\
\hline
\end{tabular}

D Trust

\begin{tabular}{|c|c|c|}
\hline Been reduced & Stayed the same & Has increased \\
\hline 0 & $2^{*}$ & 6 \\
\hline
\end{tabular}

* always used them \& good

E Responsiveness

\begin{tabular}{|c|c|c|}
\hline Been reduced & Stayed the same & Has increased \\
\hline 0 & $1^{*}$ & 7 \\
\hline
\end{tabular}

* always used them \& good

F Engagement 


\begin{tabular}{|c|c|c|}
\hline Been reduced & Stayed the same & Has increased \\
\hline 0 & $1^{*}$ & 7 \\
\hline
\end{tabular}

* always used them \& good

G Confidence in engaging with the lawyer at the legal service

\begin{tabular}{|c|c|c|}
\hline Been reduced & Stayed the same & Has increased \\
\hline 0 & $1^{*}$ & 7 \\
\hline
\end{tabular}

* always used them \& good

$\mathrm{H}$ Knowledge of their rights and responsibilities and the rights and responsibilities of others

\begin{tabular}{|c|c|c|}
\hline Been reduced & Stayed the same & Has increased \\
\hline 0 & 2 & 6 \\
\hline
\end{tabular}

I Confidence in knowing when to seek and seeking legal help

\begin{tabular}{|c|c|c|}
\hline Been reduced & Stayed the same & Has increased \\
\hline 0 & 3 & 4 \\
\hline
\end{tabular}

Comment: The participants who indicated their confidence and engagement had stayed the same indicated they had been using Consumer Action's SCs prior to 2017. The remaining participants overall reported an increase in all the indicators in relation to trust, confidence, responsivity, knowledge, engagement and a decline in levels of their stress and anxiety as a result of their interaction with Consumer Action.

Select the main client you have had. Have you noticed any of the following for your client through your professional support of them:

J Clients more knowledgeable about where to go for services

\begin{tabular}{|c|c|}
\hline Yes & No \\
\hline 8 & 0 \\
\hline
\end{tabular}

K Clients more knowledgeable about their options and more skilled over time

\begin{tabular}{|c|c|}
\hline Yes & No \\
\hline 8 & 0 \\
\hline
\end{tabular}

L Flow on effects for family members of any of the above-mentioned.

\begin{tabular}{|c|c|}
\hline Yes & No \\
\hline 7 & $1^{*}$ \\
\hline
\end{tabular}

*They had no family which formed part of their problem

M Client's sense of hope 


\begin{tabular}{|c|c|c|}
\hline Been reduced & Stayed the same & Has increased \\
\hline 0 & 0 & 8 \\
\hline
\end{tabular}

Comment: All the participants reported an improvement in their clients' social determinants of health, including levels of hope, stress, knowledge, empowerment and flow on for family as a result of Consumer Action working as a MDP in the interventions.

Question N Since the beginning of the Project has it led you to change your practice since the beginning of the project until now e.g. referrals, knowing how to identify a legal problem, where to go with a legal problem, use of secondary consultations?

\begin{tabular}{|c|c|}
\hline Stayed the same & Has increased \\
\hline 1 & 7 \\
\hline
\end{tabular}

Question 9 Do you think this (systemic work, sic) has an impact?

\begin{tabular}{|c|c|}
\hline Yes & No \\
\hline 8 & 0 \\
\hline
\end{tabular}

Question 10 Is it important (systemic work, sic) to take such action, in your view to better support your client?

\begin{tabular}{|c|c|}
\hline Yes & No \\
\hline 8 & 0 \\
\hline
\end{tabular}

Question 11 Is it important to take such action (systemic work, sic), in your view to better support people experiencing FV in general?

\begin{tabular}{|c|c|}
\hline Yes & No \\
\hline 8 & 0 \\
\hline
\end{tabular}

Question 12 From a client point of view have you seen any detriments from the project intervention?

\begin{tabular}{|c|c|}
\hline Yes & No \\
\hline 0 & 8 \\
\hline
\end{tabular}

Comment: A significant number of participants reported a change in their practice since the project's commencement in 2017 (when it was funded). This is an indication in public health research of a service that is having a positive impact. ${ }^{\text {xxi }}$

\section{TRAINING}

Question 10 Have you participated in training offered by the project?

\begin{tabular}{|c|c|}
\hline Yes & No \\
\hline 5 & $3^{*}$ \\
\hline
\end{tabular}

* all said consider SC a form of on the job training in time poor work 


\section{a. Has this enhanced your ability to assist clients with their non-legal needs}

\begin{tabular}{|c|c|}
\hline Yes & No \\
\hline $5^{*}$ & $3^{* *}$ \\
\hline
\end{tabular}

*Of those respondents that said YES in question referred to secondary consultation

** Have not done formal training so this reflects the above response

(See case studies above)

Comment: Most participants had difficulty recalling training by Consumer Action. They had to be prompted to recall training and some looked at the diary. Many $(5 / 8)$ had not realised that Consumer Action had participated in providing training or materials for it and scenarios. This was likely a result of much of the training being provided in collaboration with lead agencies. This again, highlights the difficulty of trying to untangle who has done what in service collaborations. With further thought participants commented that scenarios and some of the presenters were probably from Consumer Action and they had not realised this. The benefit for agencies like Consumer Action in tracking a professional's journey from training to SC, is it allows and agency to demonstrate the impact of their work to the organisation, community and funders. It may only be a contributing factor to a worker but, a factor nonetheless. Better data collection can only go part of the way in resolving this. For example, who attends training and when) and analysis (tracking a worker's interaction with over time to understand whether they are more likely to contact the worker advice service after attending training etc.) From a research evaluation point of view this information could still be done by de-identifying the person through a flagging or numbering the participants through the process and still tracking them along the trajectory of their interactions. In genuine integrated service delivery, if it is seamless and holistic, it can become harder to attribute outcomes to specific service inputs. This is consistent with findings in the interdisciplinary research in health service studies worldwide. $^{\text {'xvii }}$ The key point however is to have a positive, responsive, seamless and effective service experience for clients and their supports. The RCIFV recommends non-siloed integrated service delivery.

\section{Qualitative Data 2019 from Interviews}

B Prior to the project being set up at the beginning of 2017, do you think you would have been able to assist this client in the way that you have?

All participants $(8 / 8)$ were unaware of there being a specific project or that it was funded. As noted in the previous 2017 evaluation this is the product of Consumer Action providing services in an integrated manner so that there is a non-siloed and seamless experience for people contacting Consumer Action in line with the recommendations of the RCIFV.

All indicated that, ostensibly from the period the project commenced in 2017, they had either become aware (6/8) or more aware of Consumer Action (2/8) and the role it could play in responding to family violence in debt and credit issues. Some participants indicated they had an ongoing relationship before the project (3/8). 
The remainder indicated that the role and relevance of Consumer Action in offering tailored support to clients in debt and credit matters had come to their attention since the project commenced (5/8). Most indicated that although not aware of specific project funding they felt that Consumer Action was able to offer more and deeper support for family violence victim survivors than previous to 2017. One participant indicating she had always worked closely with them on a range of matters and had noticed no difference. 1/8 was not working in Victoria in 2017 and so had not been aware of Consumer Action's relevance until the following year.

Comment: Where an organisation provides seamless service in an integrated way it is difficult to then try to untangle aspects of the service that attach to specific funding. The framing of this question seeks to elicit whether the project has made a difference since 2017 in service take up and awareness, as it has, this is suggestive that the FV funding has had an impact.

C What, if any, have been the benefits for you as this client's worker/professional support of having their legal issues responded to in the context of multi-disciplinary practice? E.g. training, support through process, secondary consultation?

Participants reported the following benefits:

- All participants said that the access to secondary consultations was pivotal as it is timely and given their caseloads and being time poor it was efficient (8/8). Many said there had been ongoing additional support for their clients from Consumer Action $(5 / 8)$ and the remaining participants after initial help handled the matters on their own (3/8) but knew they could check back in if needed.

- An increase in confidence to provide client information or to refer $(7 / 8)$

- We came up with more creative solutions as putting two disciplines and experiences together which is the value of such multi-disciplinary practice $(3 / 8)$

- The integrated nature of the service makes it easy to get a response and get clear guidance earlier and often before clients' state of stress elevates even further (5/8).

- It means clients who are not accustomed to or trusting of lawyers can work with trusted family violence supports to navigate complex systems. (4/8)

- We can have the direct conversation with the lawyers, and this means the clients are not exhausted by telling their story over again and having to navigate even more service systems which is overwhelming when family violence will mean they have many issues to sort out - housing, income, children, school fees. (7/8)

- Enables me to take on more cases that I would otherwise as I can put the technical arguments and be armed to address pushback from companies and regulators. (3/8)

- Helps me advocate on a different level knowing I have had legal advice (5/8)

- If I indicate I have taken legal advice sometimes the other side are more inclined to listen. (1/8)

- Now we know more options (4/8)

- Comprehensive and makes me ask and think of new approaches and new questions to ask than I would have thought to ask before (2/8)

- Step by step advice can be critical as things change and so SC enable us to take it 
slowly when very complex. (7/8)

- Risk longer term can be managed as there may be more financial implications

- They have so little money so being able to get refunds, loans cancelled, financial hardship dispensation, debt cancellation and debt-waiver leaves more income for food, school fees and health care. (6/8)

CDo you use the SC information for more clients than you seek the initial advice for?

- Definitely (8/8)

- Spread the word about both the service Consumer Action can provide to my team and other workers

- Advice management of how Consumer Action can assist their workforce to advise clients

- I use the information for many more clients downstream over and over checking in again when I need to (8/8)

- The advice goes into a knowledge bank for other clients

$D$ Do you think that providing SC to non-legal professionals is enabling more clients to be reached than would otherwise be the case without the SC.

- The lack of a turn away policy and ease of access for us workers means we can help more clients quickly than waiting for access to a lawyer normally which can be impossible or hard to navigate and when funds are in short supply.

$\circ \quad$ I can get a timely and quick response. Even if they lack expertise they will find out and get back in touch quickly. This is reassuring for clients who are traumatised and stressed, and it makes us look better, build trust in us and lawyers and makes us knowledgeable too.

- As community agencies we don't have access to lawyers for this sort of advice nor do our clients so it is reaching many more people who otherwise would not get legal help on how to access their rights. (7/8)

- If you think of the number of our team and people like me who use the information and advice from Consumer action over and over again then yes its reaching many more than the initial client (6/8)

- Our clients would not otherwise access legal advice or even the range of options and ways of navigating the laws and making arguments to these companies who will not listen to our family violence clients if they have the energy to ask. (5/8)

- These companies and the perpetrators of violence use their power to manipulate and exploit the vulnerable and so being able to quickly make a call get a timely response is critical to safety, housing and calling them to account. $(4 / 8)$

Question 2 What, if anything, has the project and secondary consultation (SC) meant, in your own experience, to your practice? If so, describe the sort of situation without giving away any information that will identify a client. 


\section{Responses include:}

Enables quick contact to get advice often in a time when clients are in crisis

$>$ Help get waivers for irresponsible lending which gives more money for victims to survive and support families.

$>$ The way I write letters had changed. I ask more and relevant questions to pave the way and have learned this from the team at Consumer Action.

$>$ Selfcare - the access helps me sleep at night and not have to worry so much about my clients assured they have options to pursue

$>$ More confident in taking issues further than I would think to do so otherwise

$>$ I am more able to respond to the 'no' from agencies who claim they cannot help when they can.

$>$ Made my life easier as I trust the advice and consider it helpful

$>$ Enhances knowledge and confidence in negotiations as I know the specific provisions, obligations available to clients to access on family violence when they have so many issues with lenders. It means I can ensure agencies adhere to their guidelines and protocols.

$>$ Banks are not so responsive. Often the guidelines are in place but it's still difficult for clients to know about or access them without strong advocacy. They get push back still even though there was the RCIFV.

$>$ Timeliness is so important in Family Violence

$>$ I am more confident to ask random questions and Consumer Action responds. At the same time, I can see they are learning too. I can proffer my expertise around impacts of family violence and they can also change their practice. Lawyers can sometimes be too dismissive and technical so, sometimes I have to push the lawyers outside their own comfort zones to get them to see complexity and the plight these clients are in. Then we can fully problem solve.

$>$ It's integrated. Therefore, I was not aware of the additional family violence funding. In the end the clients do not care where the funding comes from in times of crisis, they just need help and being confident to have Consumer Action to turn to or be in the background has been critical over the past two years.

$>$ It enhances client outcomes. I get more knowledge, and this gives me more confidence to help the client in a meaningful way rather than just sending out fact sheets for us to work it out as they used to. Clients need accuracy and advice tailored to their needs.

$>$ I don't have to pretend or worry I am on the wrong track as now I have somewhere to go to check in and find expertise. It's phenomenal and reduces my own insecurity in what is a very challenging nature of the work in family violence with so much risk and at stake.

$>$ Clients need accuracy and to find out things quickly which is why the responses of the lawyer needs to be comprehensible and useable and practical

Comment: Questions C, D and 2 responses suggest that SC are efficient and reach many other people downstream. They reported that by providing one SC for a client, participants 
were using the same information for many other clients downstream. They also noted that share this information with their teams and agency.

This indicates that $\mathrm{SC}$ is an effective and efficient means of reaching a larger number of people and so, is a good and resource sensible way of reaching many excluded people who may not otherwise have the wherewithal to reach a lawyer. This is particularly important in time of stretched community and legal assistance services.

All participants noted that not all clients felt comfortable seeing a lawyer or had experienced trauma in dealing with the legal system or its agencies; or thought they would need to pay for a lawyer and so this was a barrier to them seeking help from lawyers. All participants thought that SC overcomes this barrier with either borrowed trust between the professionals being an enabler, or a client who is too distressed to see a lawyer and repeat their story being able to work through their trusted intermediary to gain access to the legal help they would not otherwise be able to avail themselves of. This is consistent with other research in Australia and Canada. ${ }^{\text {xxviii }}$

All participants noted that $\mathrm{SC}$ needs to be done well and be suitably tailored. All reported they would check in with lawyers at Consumer Action in the event of changed circumstances or the passage of time and felt comfortable doing so.

Question 5 What has been the value to you of secondary consultations if you have received any?

- Look now to legal perspectives and options that never been exposed to. So often everything is seen from a family law prism and earlier opportunities to get out of debt are missed and yet these are critical for safety and escape and support for children

- Confidence has increased and stress levels for me and my clients have decreased

- Enable me to honour my duty of care

- Now I can talk to a lawyer easily at Consumer Action through Secondary consultation I know where the ethical boundaries sit and access to legal advice helps navigate this

- Can confirm my opinion and then I know I am on the right track

- Secondary consultation gives me information to pass onto clients that is structured and practical and reduces their distress

- Secondary consultations are a quick, timely and easy way for clients in crisis and at risk can get the help they need. The simplicity and lack of intake process also means that it is more accessible and not as hard to navigate to get immediate help as other services can be.

- When the lawyers make it comprehensible and use dots points it also helps the clients feel more empowered.

- Secondary consultations are crucial in this family violence space as they are ongoing in nature and so if things take a curly turn, we can get back in touch quickly.

- Makes me more confident in my advice

- It has helped me to continue with a case when otherwise I would have thought I had hit a dead end

- It's valuable, an incredible offering. It's also good though when Consumer Action can 
take on a case as sometimes it may not be enough

- Great especially when clients are not able or are reticent to speak to a lawyer themselves - all about power dynamics.

- Secondary consultations are a clear, quick and concise way of getting practical help, so you can keep going back with other client issues as it builds trust for both the worker and the client.

- Knowledge is power

- I had a recent secondary consultation where the lawyer was too abstract and used jargon. This was not great. The lawyers need to be constantly trained. The advice they give to workers must be practical, understandable and be able to be utilised in terms of steps to be taken, next steps and in language and with a manner that gets what our clients need. The lawyer seemed not to understand we are experts in family violence and what might be needed to offer proper support. This experience is rare for Consumer Action. Do new staff get the right induction? It's all about the need to work as a team with mutual respect.

- Flow on effect of secondary consultations is for so many other clients not just for the one we make the call for. It's effective and efficient and a great use of resources to use Secondary consultations to get to more clients without the need for a lawyer each time- spread the service out well and truly beyond the one-off secondary consultations

- Secondary consultations are key, but they must be done well as trust can easily be lost, though they (Consumer Action) are establishing such good rapport one bad one an aberration but there is a skill to doing them well. The person must be a human and get context and use plain and accessible language and give practical advice.

- Secondary consultations that are done well, take into account the individual circumstances of the client around housing, kids, fear, power and anxiety, ill health and stress. No legal advice is complete without a consideration of such factors as they are interconnected and co-dependent.

- Secondary consultations I have done have been clear and enable me to plan a strategy for the client. Sometimes this extend to how to frame a letter to get the right response.

Question 6 Do you wish to comment whether you believe secondary consultations are an integral part of the collaboration with professionals/staff at your agency to advocate for their clients with family violence and debt and credit issues?

$\checkmark$ Flow on effects to worker client and clients' kids

$\checkmark$ Fundamental to my practice now. I was not aware this all was made possible by additional funding, but I can see the difference in the service response that it has made. Before the funding the support was often fleeting. Now its able to be more tailored and the support is deeper. This is critical if we are going to reduce the impacts on women and children fleeing their children and a simple thing like secondary consultations makes such a difference as well as the additional case support on family violence, I have seen in the past two years. 
$\checkmark$ Too many agencies use conflicts to avert helping even if things are unrelated and so it is critical to have access to secondary consultations as a workaround. It is an access to justice issue

Comment: SC are seen by all participants as fundamental to responsiveness, trust and immediate, tailored and relevant advice

Question 7 Through the project have you collaborated on advocating for work that impacts on the broader community' or 'actions that change laws, systems or policies that impact on the broader community by joint action between your agency and Consumer Action? (E.g. submissions to government or a statutory body, test case, letter arguing for a change on practice, the law or its administration, document articulating client/patient experience of the system and requesting a change).

- Yes, as experts we have knowledge of family violence and its impact, working alongside Consumer Action has enabled a sharing of practice and they know a lot about systems reform and so the combined effort is much more productive.

- Shared stories in Canberra with clients, Consumer Action and ourselves. It is great. Politicians in Canberra are too removed and don't get it and so this was a chance to bring them down to our reality. Unless you do this, they don't get it. It is also empowering for clients to have this voice and they are integral to such work.

- Provided client case studies to submissions

- Not been asked to be involved but would love to be asked as it might help me survive the day to day and be able to see myself as a part of the much- needed broader change.

- Clients participating in such action makes them feel better and as if someone is listening to them so I would also encourage strategies that involve them.

- I would like to be involved it would be nice to be asked.

- I have contributed case studies, but the feedback loop is poor as we go to a lot of effort but then do not get updated on where it goes. Consumer Action should have a better feedback loop (3/8)

Comment: The data indicates that the inclusion of the voice of those experiencing family violence is critical in any policy action or reform. Participants all want to know more about the work of Consumer Action in policy and campaigns and how they and their clients can participate, mindful of client safety and risk. All said it was empowering.

Improvement: Consumer Action needs to be better at providing feedback to non-legal professionals about their campaign work but also to those who participate in their submissions and provide case studies and include them more often in their work with decision-makers. One participant remarked on how empowering this experience was for her and her client when they visited Parliament House with Consumer Action.

Improvement of Industry: There is also some suggestion that banks and other financial institutions are still not as responsive as they could be and are not adhering to protocols set up after the RCIFV. This contracts with a small data sample in the projects 2018 'check-in' that front end services were becoming more responsive due to the RCIFV. This will need 
constant monitoring, proper supervision by industry, training and awareness and accountability from industry in banking and finance.

Question 13 As a result of the project have you seen any 'breakthroughs' for your client?

\section{(see case studies)}

Question O Do you receive/ or think there ought to be systemic action to assist in self-care of the worker (i.e. prevent burn out) for your self-care as a worker?

Yes $8 / 8$

\section{Explain}

This is traumatic work, so we need it. $8 / 8$

My agency is great, and the managers vary work from time to time to avert vicarious trauma for the repetitive horror stories which take their toll, but I see other agencies who do not do it well.

This is critical but funders don't include it in their model. $6 / 8$

Management often don't give the space for recovery and joint debrief. It's not about the individual it's the work which can take its toll as family violence can be confronting no matter how experienced you are and its day in day out. 5/8

Comment: Self-care in this complex and traumatic area of service delivery was noted by all participants. They also stated it should not be individualised as the 'workers problem' but rather be seen as something requiring organisational support, professional development and trauma informed practice and variations in work.

Question 15b What factors/tools, help/could help you in making effective referrals?

- Timeliness

- Clarity

- Streamlined process

- Hurdles to jump mean clients don't get interventions at critical times. In family violence timing can be critical.

- That intake and assessments are not complicated - paperwork can hold things up. If needed, then needs to be quick and not block access. Consumer Action are great at this.

- Holistic

- Trust is critical $8 / 8$

- Good service experience

- Treated with respect $7 / 8$

- Previous positive experience of secondary consultations means my team and others I speak to in other agencies will start to use the service. 
This data is substantially summarised from the Substantial Majority of Participant Reponses

\section{Case Studies extracted from Interviews with non-legal professionals}

\section{Case Study One}

Client was in dire circumstances and was not herself confident to approach lawyers. The client was extremely vulnerable. I was able to use secondary consultations to help the client navigate the many minefields in her debt matters. I was able to relay constant queries back to the Consumer Action team and have these addressed. They also raised other options for me to discuss with the client that I would have otherwise missed. The client was reassured as she knew I had this technical support. The way the companies were dealing with the client was exploitative and causing trauma additional to the family violence. We navigated the stigma and her fear of lawyers to get a result by working in collaboration. With the legal angles, we were able to reduce the debts and assert her other rights. The legal system is so complicated for women like her and so it was a big relief that I could quickly get a response from the lawyers.

\section{Case Study Two}

A victim of family violence had a car loan but was not able to afford it and the insurances that could help her in dealing with the situation. There was irresponsible lending and so we were able to demand a refund. The client got her insurance monies back and had more to spend on essentials such as food and utilities.

\section{Case Study Three}

A client had family violence issues from her ex-partner. She had two young children. They had to move around a lot to stay safe. A debt was secured in her name and her ex-partner had access to the goods that were purchased by the debt. She would never have been able to afford legal advice and so the Consumer Action support through secondary consultation, I could get for her was invaluable. I am new to my role and I did not know what to do to help her. We secured a debt waiver. This meant the family could stop living 'hand to mouth', reduced their overdue payments and could afford their grocery bills to feed the family. The debt had been causing mental health issues and once the debt was waived, the mother could focus on her health and the well-being of her children due to the reduction in stress and anxiety caused by the debt and lack of income for necessities.

\section{Case Study Four}

A lady had insurmountable debts. Worry led to her admission in a psychiatric institution. She suffered from depression and was also worried about her teenage daughter. The family violence had deeply affected the mother. Over time and with legal information about her rights we built her trust and she disclosed more about her circumstances that was highly personal including suicidal ideation. With the information and support provided by Consumer Action as well as the secondary consultations we were better armed to take action and work to get her debts waived. She felt more reassured and eventually found a full-time job. Before, she had been too overwhelmed to do so. 


\section{Case Study Five}

Mother fleeing family violence. Her child had a behavioural disorder. Working with Consumer Action we managed to get the debt waived. The lessening of the financial strain led the client to report that her child's condition had lessened in its severity and that outcomes included payment of the registration and an ability to get the kids to school more easily and less sickness.

\section{Case Study Six}

A client experiencing family violence had a small amount credit contracts taken out over a small period. She never had enough money to cover all the debts and no income to make payments. The companies were demanding payment and the client was stressed and left with no money to pay the rent. The client was getting stressed and anxious at the unrelenting demands for payment. Consumer Action assessed the facts and confirmed they gave rise to irresponsible lending on the part of the companies. The debts were waived, and the client's mental health improved as she did not have to stress about making payments and keeping a roof over her head.

\section{Case Study Seven}

Appliances were in the family violence perpetrator's name. The client needed help to get the company to honour the warranty. The client did not know where to start to get the warranty honoured. Consumer Action helped to unravel the legal arguments including technical aspects around 'technical abuse.' They helped explain complex concepts in the law in plain English and then this multidisciplinary team were able to get the company to honour the warranty. Sometimes, the very mention of family violence nowadays makes people in some agencies like the banks and finance companies 'roll their eyes' but it has an impact. These simple things can add up especially when people do not have enough to live on and rely on appliances.

\section{Case Study Eight}

I had two clients for five years each with intractable family violence situations. Previously each had been told their cases were hopeless. Then Consumer Action came in and have got their gas and electricity connected.

\section{Case Study Nine}

In this case we co-ran the case with Consumer Action. It's great when it's a three-way conversation with the lawyer, us and a client. The client feels more confident and they also feel empowered as they have a lawyer. They hear they have rights and we can discuss the wording of a letter which makes them see they can question and challenge companies. This is empowering.

\section{Case Study Ten}

The home had been owned outright but the partner took out debts using the home as security. There was family violence. The partner left and was bankrupted. My client had a disability and was left on a meagre pension. She was down as the co-borrower. This case took 
time to unravel with multiple contracts and loans and it took a lot of work to work out what had occurred in the case and find all the documentation. Consumer Action was able to leverage its connections with industry to get the banks and financiers to examine the case and the lady got her title to the property back with clear title and the debts were written off.

\section{Case Study Eleven}

Client had dealings with a motor car finance company. As a result of family violence, she had to cease work and manage with two children. She had more than paid for the vehicle and the company refused to acknowledge her change in circumstances and sent the repossession man around. Consumer Action took the matter to the regulator who refused to budge saying the client had originally had use of the vehicle. Consumer Action pursued the case and the client ended up retaining the car, gaining monetary compensation and was able to take the children on a much-needed holiday for a few days to regroup and recover from all the trauma the family violence had placed on the whole family.

\section{Case Study Twelve}

The client's car was insured. Her car was damaged by the perpetrator of family violence. The insurer refused to honour the claim without extensive evidence. Her safety and that of her children was placed further at risk as she had no access to the car to get away or get help and support as per her safety plan. Consumer Action spoke to the insurer and the client is now liaising with the insurance company about compensation.

\section{Case Study Thirteen}

Perpetrator gained access to the client's $A B N$ and obtained goods which he then sold. He bought the goods in the name of her business and in her name. It is a complicated case and Consumer Action are assisting me with the legal technicalities.

Quantitative Aggregated Service Data Collected by Consumer Action Over the Life of the Project: 13 November 2017 until 19 November 2019

- Part 1: Data for $1 / 12 / 17-10 / 12 / 18$

- Part 2: Data for $12 / 12 / 18-20 / 11 / 19$

- Part 3: Aggregated data for 1/12/17-20/11/19 
1. Data on number of cases where there has been legal advice and assistance cases to community workers involving clients with consumer, credit $\&$ debt issues arising out of family violence. (Contracted)

\begin{tabular}{|l|l|}
\hline Source organisation & Number of secondary consults \\
\hline Financial counsellor & \\
\hline Lawyer & 52 \\
\hline Other & 28 \\
\hline $\begin{array}{l}\text { Other not for profit workers (including } \\
\text { family violence support workers) }\end{array}$ & 5 \\
\hline Not recorded & 9 \\
\hline TOTAL & 5 \\
\hline
\end{tabular}

From trainings (approximate):

- $\quad$ Barwon: 7

- Djirra: 4

- Hume: 6

2. Data on the number and type of referrals relating to family violence matters both into and out of the organisation. (Contracted)

$\underline{\text { Total referrals (consumer enquiries received): } \mathbf{1 0 0}}$

Referrals in came from:
a. ACCC: 1
b. CAAP advocate: 1
c. CALC website: 2
d. CALC outreach or training: 1 (Barwon)
e. CAV: 10
f. Lawyers: 17
g. FC agency: 11
h. FOS: 7
i. $\mathrm{NDH}: 24$ 
j. Not stated: 1

k. Other: 1

I. Other community agency: 5

m. VALS: 2

n. VLA: 16

o. Not recorded: 1

From trainings (approximate):
a. Barwon: 1
b. Djirra: 1
c. Grampians: 1
d. Hume Riverina: 5

Referrals out went to:
a. CALC website: 1
b. $\mathrm{ClO}: 2$
c. CLC: 4
d. FC agency: 8
e. FOS: 4
f. NDH: 3
g. None: 44
h. Other: 1
i. Other community agency: 1
j. Other dispute resolution service: 1
k. Privacy commissioner: 1
I. Private lawyer: 3
m. Self-client will help themselves: 15
n. TIO: 1
o. VCAT: 3
p. Not recorded: 8 
ANU School of Legal Practice

Australian

ANU CRICOS Code 00120C

National

ORCID ID 0000-0002-6371-2975 
1. Data on number of legal advice and assistance cases to community workers involving clients with consumer, credit $\&$ debt issues arising out of family violence. (Contracted)

\begin{tabular}{|l|l|}
\hline Source organisation & Number of secondary consults \\
\hline $\begin{array}{l}\text { Other not for profit workers (including } \\
\text { family violence support workers) }\end{array}$ & 13 \\
\hline Financial counsellors & 86 \\
\hline Lawyers & 20 \\
\hline Other & 1 \\
\hline Not recorded & 18 \\
\hline & \\
\hline TOTAL & $\mathbf{1 3 8}$ \\
\hline
\end{tabular}

Comment: Unfortunately, there was little breakdown of the 'Not recorded' or 'other'. The author has written about this as a problem in legal assistance data elsewhere. ${ }^{x x i x}$ In the indepth interviews $4 / 8$ people interviewed were not financial counsellors and worked in family violence as support workers, psychologists or as counsellors.

The author has asked that service data, in future, record the nature of the professional to gain greater insights into the variety of non-legal professionals the project is reaching. This did not allow a comparison with 2017 data to see if there was a greater uptake beyond financial counsellors since the project's inception, other than the feedback in the in-depth interviews.

The in-depth interview data was suggestive of a range of agencies and types of professionals being reached then before the project. This small sample of participants however, does not enable any further conclusions or extrapolation about reach in terms of other than financial counsellors.

From trainings, (approximate) Consumer Action staff reported that the figures are very difficult to ascertain from Consumer Action's new system and that staff have taken time to learn and adjust to the new system and there are problems distinguishing between sources of referrals. It was noted that the figures are likely to be an underestimation):

- Barwon: 1 
- Hume: 4

- Grampians: 1

- Prisoners: 1

2. Data on the number and type of referrals relating to family violence matters both into and out of the organisation. (Contracted)

$\underline{\text { Total referrals (consumer enquiries): } 109}$

Referrals in came from:
a. AFCA: 3
b. CAAP advocate: 2
c. CALC/ CALC website: 5
d. CAV: 9
e. CLC: 13
f. FC agency: 5
g. $\mathrm{NDH}: 29$
h. Not stated: 5
i. Other: 6
j. Other community agency: 6
k. Sister's Day Out: 1
l. VLA: 8
m. Not recorded: 8
n. Private lawyer: 2
o. VCAT: 1
p. Self - has previously contacted CALC: 6

From trainings Consumer Action conducted (very approximate -figures are due to difficulty in ascertaining from the new data system (see comments above), so these figures may be an underestimation):

\section{○ Hume: 1}

Referrals out went to:
a. AFCA: 9
b. CALC website: 2
c. FC agency: 7
d. $\mathrm{NDH}: 2$
e. None: 33
f. Other:4
g. Private lawyer: 6 

h. Self- client will help themselves: 11
i. VALS: 1
j. Not recorded: 33
k. VCAT: 1 
3. Data on number of cases where there has been legal advice and assistance cases to community workers involving clients with consumer, credit $\&$ debt issues arising out of family violence. (Contracted)

\begin{tabular}{|l|l|}
\hline Source organisation & Number of secondary consultations \\
\hline Financial counsellor & 138 \\
\hline Lawyer & 48 \\
\hline Other & 6 \\
\hline $\begin{array}{l}\text { Other not for profit workers (including } \\
\text { family violence support workers) }\end{array}$ & 22 \\
\hline Not recorded & 23 \\
\hline & 237 \\
\hline TOTAL & $\mathbf{2 3 7}$ \\
\hline
\end{tabular}

Comment: Again, there was little breakdown of the 'Not recorded' or 'other'. In the in-depth interviews 4/8 people interviewed were not financial counsellors and worked in family violence as support workers, psychologists or as counsellors.

The author has asked that service data, in future, record the nature of the professional to gain greater insights into the variety of non-legal professionals the project is reaching. This did not allow a comparison with 2017 data to see if there was a greater uptake beyond financial counsellors since the project's inception.

From training, Consumer Action conducted (approximate).:

- Barwon: 8

- Djirra: 4

- Hume: 10

- Grampians: 1

- Prisoner advocates: 1

Again, the author has been advised by Consumer Action personnel the figures are very difficult to ascertain from the new data system and user adjustment to the new system and, again, distinguishing between referrals from multiple sources and therefore may be an underestimation) 
4. Data on the number and type of referrals relating to family violence matters both into and out of the organisation. (Contracted)

Total referrals (consumer enquiries): 209

Referrals in came from:
a. ACCC: 1
b. AFCA: 3
c. CAAP advocate: 3
d. CALC website: 7
e. CALC outreach or training: 1 (Barwon)
f. CAV: 19
g. Lawyers: 32
h. FC agency: 16
i. FOS: 7
j. NDH: 53
k. Not stated: 6
I. Other: 7
m. Other community agency: 11
n. Sisters' Day Out: 1
o. VALS: 2
p. VLA: 24
q. Not recorded: 9
r. VCAT: 1
s. Self - has previously contacted CALC: 6

Referrals out went to:
a. AFCA: 9
b. CALC website: 3
c. $\mathrm{CIO}: 2$
d. CLC: 4
e. FC agency: 15
f. FOS: 4
g. $\mathrm{NDH}: 5$
h. None: 77
i. Other: 5
j. Other community agency: 1
k. Other dispute resolution service: 1
I. Privacy commissioner: 1
m. Private lawyer: 9
n. Self-client will help themselves: 26
o. TIO: 1
p. VALS: 1 
q. VCAT: 4

r. Not recorded: 41

From training (very approximate), Consumer Action staff indicate these figures are very difficult to ascertain from the new data system and therefore may be an underestimation):

- Barwon: 1

- Djirra: 1

- Grampians: 1

- Hume Riverina: 6

Training Survey Collected by Consumer Action Over the life of the Project 13 November 2017 until 19 November 2019

\section{Training Materials}

Materials developed through the project are contained in Appendix 1 to this report. These include fact sheets and information around credit and debt and problem identification and pathways. Self-help and fact sheets alone are not enough on their own ${ }^{\mathrm{xxx}}$ but provide a useful tool for community professionals to be guided in how they support their clients. The need for the resourcing of trusted intermediaries and for them to have access to such tools is especially the case given the social exclusion, dislocation and disempowerment caused by family violence.

The author is also a Higher Education expert. ${ }^{x x x i}$ The training materials listed in Appendix 1 have been scrutinised. The assessment is they are concise, readable, accurate and useable by non-legal professionals as they avoid legal jargon. A good illustration of this is the excerpt from the issue spotting document item 1 in Appendix 1 entitled Financial Recovery' Guide which states 'Joint bills Has your client been left with unaffordable telco and utility bills after the breakdown of their relationship?' They are practical for their target audience, namely community professionals and their clients.

The Practice Notes by necessity require a depth of information but the way information is presented is not overwhelming. The provision of hyperlinks to complaints processes makes the Practice Note a quick, one-stop and ready resource for time poor professional supports and 'trusted intermediaries' like family violence professionals.

\section{Training Offered by Consumer Action on Debt and Credit Issue for Family Violence}

The data from the training surveys is however more useful.

It is important to note that service is not just about numbers but also about the quality and usefulness of the service being delivered and so the data below from pre and post training is more informative than the data above. 


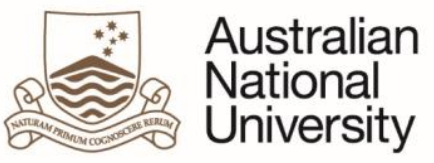

Australian

University
ANU School of Legal Practice

ANU CRICOS Code 00120C

ORCID ID 0000-0002-6371-2975

Trainings from 17 November 2017 - 19 November 2019 (see service data on evaluation survey responses and attendance below):

1. Wodonga- Hume Riverina Community Legal Service

2. Geelong- Barwon Community Legal Centre

3. Djirra - Aboriginal Family Violence Prevention Legal Service

4. Greensborough- Nillumbik Family Violence Network

5. Stawell- Grampians Community Health

6. Rumbalara Aboriginal Cooperative \& Goulburn Valley CLC (only one worker attended-see mid-project report)

7. Prisoner advocates- various organisations represented

8. Morwell- Queen Elizabeth Centre - to family and parenting workers including Aboriginal services

9. VLA Family Law Forum (approx. 200 attendees)

10. WIRE building financial capacity workshop - various organisations represented

11. Sale- homelessness and family violence workers (in partnership with Tenants Union Victoria)

\begin{tabular}{|l|l|c|}
\hline Date & Name of the Session & $\begin{array}{c}\text { No. of } \\
\text { participants }\end{array}$ \\
\hline $14-S e p-18$ & Financial recovery from family violence-Djirra & 8 \\
\hline $14-S e p-18$ & Financial recovery from family violence- Nillumbik & 18 \\
\hline $10-$ Oct-18 & Financial recovery from family violence- Grampians & 5 \\
\hline $13-F e b-19$ & $\begin{array}{l}\text { Round table training -Financial recovery from family violence for } \\
\text { prisoner advocates }\end{array}$ & 10 \\
\hline $19-$-Feb-19 & Financial recovery from family violence- Morwell & 6 \\
\hline 21-May-19 & WIRE- building Financial capability in financial abuse & 13 \\
\hline 19-Nov-19 & Training to family violence and homelessness workers - Sale & 45 (approx) \\
\hline
\end{tabular}

\begin{tabular}{|l|c|}
\hline Engagement with Consumer Action & Responses \\
\hline Before the session had heard of CALC & 7 \\
\hline Before the session had not heard of CALC & 3 \\
\hline I have referred & 2 \\
\hline I have called & 3 \\
\hline
\end{tabular}


Australian

National

University
ANU School of Legal Practice

ANU CRICOS Code 00120C

ORCID ID 0000-0002-6371-2975

\begin{tabular}{|l|c|}
\hline I have neither referred nor called & 6 \\
\hline
\end{tabular}

\begin{tabular}{|l|c|c|c|c|c|}
\hline $\begin{array}{l}\text { Please answer the question on a scale of } 1 \\
\text { to } 5 \text { with } 1 \text { being disagree } \mathbf{2} \text { being } \\
\text { somewhat Disagree } \mathbf{3} \text { being neutral } \mathbf{4} \text { being } \\
\text { agree and } \mathbf{5} \text { being strongly agree }\end{array}$ & $\begin{array}{c}\text { Strongly } \\
\text { Agree }\end{array}$ & Agree & Neutral & Disagree & $\begin{array}{l}\text { Strongly } \\
\text { Disagree }\end{array}$ \\
\hline I understand how CALC can assist my clients & 7 & 3 & & & \\
\hline The content of training was what I expected & 3 & 3 & 3 & & \\
\hline The training assisted me in learning & 8 & 2 & & & \\
\hline The Presenter kept me engaged in the topic & 8 & 2 & & & \\
\hline Training met my needs & 7 & 3 & & & \\
\hline $\begin{array}{l}\text { The training content will be useful in my } \\
\text { work }\end{array}$ & 7 & 3 & & & \\
\hline
\end{tabular}

Please answer the question on a scale

of 1 to 5 with 1 being disagree 2 being

somewhat Disagree 3 being neutral 4

being agree and 5 being strongly agree

How confident would feel in referring to

or calling CALC

\begin{tabular}{|l|c|c|c|c|}
\hline $\begin{array}{c}\text { Not } \\
\text { Confident }\end{array}$ & $\begin{array}{c}\text { Somewhat } \\
\text { Confident }\end{array}$ & $\begin{array}{c}\text { Not } \\
\text { sure }\end{array}$ & Confident & $\begin{array}{c}\text { Very } \\
\text { Confident }\end{array}$ \\
\hline & & & & 6 \\
\hline
\end{tabular}

\section{Suggestions to improve Training}

Would like to engage in these types of workshop more often to re-enforce skills and discuss issue problems that we are having.

\begin{tabular}{|l|l|}
\hline Before the session had heard of CALC & 0 \\
\hline Before the session had not heard of CALC & 6 \\
\hline I have referred & 0 \\
\hline I have called & 0 \\
\hline Neither referred nor called & 6 \\
\hline
\end{tabular}


Australian

National

University
ANU School of Legal Practice

ANU CRICOS Code 00120C

ORCID ID 0000-0002-6371-2975

\begin{tabular}{|c|c|c|c|c|c|}
\hline $\begin{array}{l}\text { Please answer the question on a scale of } 1 \text { to } \\
5 \text { with } 1 \text { being disagree } 2 \text { being somewhat } \\
\text { Disagree } 3 \text { being neutral } 4 \text { being agree and } 5 \\
\text { being strongly agree }\end{array}$ & $\begin{array}{c}\text { Strongly } \\
\text { Agree }\end{array}$ & Agree & Neutral & Disagree & $\begin{array}{l}\text { Strongly } \\
\text { Disagree }\end{array}$ \\
\hline I understand how CALC can assist my clients & 7 & & & & \\
\hline The content of training was what I expected & 3 & 2 & 1 & & \\
\hline The training assisted me in learning & 6 & & & & \\
\hline The Presenter kept me engaged in the topic & 6 & & & & \\
\hline Training met my needs & 6 & & & & \\
\hline The training content will be useful in my work & 6 & & & & \\
\hline
\end{tabular}

Please answer the question on a scale of 1 to 5 with 1 being disagree 2 being somewhat Disagree 3 being neutral 4

being agree and 5 being strongly agree

How confident would feel in referring to or calling CALC

\begin{tabular}{|l|c|c|c|c|}
\hline $\begin{array}{c}\text { Not } \\
\text { Confident }\end{array}$ & $\begin{array}{c}\text { Somewhat } \\
\text { confident }\end{array}$ & $\begin{array}{c}\text { Not } \\
\text { sure }\end{array}$ & Confident & $\begin{array}{c}\text { Very } \\
\text { Confident }\end{array}$ \\
\hline & & & 1 & 5 \\
\hline
\end{tabular}

\section{Suggestions to improve Training}

Anna was extremely helpful, and information learnt will most definitely be used in my workplace.

\begin{tabular}{|l|c|}
\hline Pre-session survey only & Responses \\
\hline Before the session had heard of CALC & 4 \\
\hline Before the session had not heard of CALC & 3 \\
\hline I have referred & 4 \\
\hline I have called & 1 \\
\hline I have neither referred nor called & 4 \\
\hline
\end{tabular}


Australian

National

University
ANU School of Legal Practice

ANU CRICOS Code 00120C

ORCID ID 0000-0002-6371-2975

\begin{tabular}{|c|c|c|c|c|c|}
\hline $\begin{array}{l}\text { Please answer the question on a scale } \\
\text { of } 1 \text { to } 5 \text { with } 1 \text { being disagree } 2 \text { being } \\
\text { somewhat Disagree } 3 \text { being neutral } 4 \\
\text { being agree and } 5 \text { being strongly agree }\end{array}$ & $\begin{array}{l}\text { Strongly } \\
\text { Agree }\end{array}$ & Agree & Neutral & Disagree & $\begin{array}{l}\text { Strongly } \\
\text { Disagree }\end{array}$ \\
\hline $\begin{array}{l}\text { I understand how CALC can assist my } \\
\text { clients }\end{array}$ & 5 & 2 & & & 2 \\
\hline $\begin{array}{l}\text { How confident would feel in referring to } \\
\text { or calling CALC }\end{array}$ & 6 & 2 & & & \\
\hline
\end{tabular}

Suggestions to improve this workshop

Most people said great work, Suggestion to provide another Aboriginal client case study

\begin{tabular}{|l|c|}
\hline Engagement with Consumer Action & Responses \\
\hline Before the session had heard of CALC & 8 \\
\hline Before the session had not heard of CALC & 8 \\
\hline I have referred & 3 \\
\hline I have called & 2 \\
\hline I have neither referred nor called & 13 \\
\hline
\end{tabular}

Please answer the question on a scale

of 1 to 5 with 1 being disagree 2 being

somewhat Disagree 3 being neutral 4

being agree and 5 being strongly agree

I understand how CALC can assist my

clients

The content of training was what I

expected

The training assisted me in learning

The Presenter kept me engaged in the topic

Training met my needs

The training content will be useful in my work

\begin{tabular}{|c|c|c|c|c|}
\hline $\begin{array}{c}\text { Strongly } \\
\text { Agree }\end{array}$ & Agree & Neutral & Disagree & $\begin{array}{c}\text { Strongly } \\
\text { Disagree }\end{array}$ \\
\hline 10 & 5 & 1 & & 1 \\
\hline 9 & 4 & 3 & 1 & \\
\hline 14 & 3 & & & \\
\hline 16 & 1 & & & \\
\hline 10 & 5 & 1 & & \\
\hline 13 & 4 & 1 & & \\
\hline
\end{tabular}


Australian

National

University
ANU School of Legal Practice

ANU CRICOS Code 00120C

ORCID ID 0000-0002-6371-2975

\begin{tabular}{|l|c|c|c|c|c|}
\hline $\begin{array}{l}\text { Please answer the question on a } \\
\text { scale of } 1 \text { to } 5 \text { with } 1 \text { Not confident } \\
2 \text { somewhat confident } 3 \text { not sure } 4 \\
\text { confident } 5 \text { very confident }\end{array}$ & $\begin{array}{c}\text { Not } \\
\text { Confident }\end{array}$ & $\begin{array}{c}\text { Somewhat } \\
\text { Confident }\end{array}$ & Not sure & Confident & $\begin{array}{c}\text { Very } \\
\text { Confident }\end{array}$ \\
\hline $\begin{array}{l}\text { How confident would feel in } \\
\text { referring to or calling CALC }\end{array}$ & & 1 & & 2 & 9 \\
\hline
\end{tabular}

\section{Suggestions to improve Training}

Most people said great information and they will use it in their work.

\begin{tabular}{|l|c|}
\hline Engagement with Consumer Action & Responses \\
\hline Before the session had heard of CALC & 0 \\
\hline Before the session had not heard of CALC & 5 \\
\hline I have referred & 0 \\
\hline I have called & 0 \\
\hline I have neither referred nor called & 5 \\
\hline
\end{tabular}

Please answer the question on a scale of

1 to 5 with 1 being disagree 2 being

somewhat Disagree 3 being neutral 4

being agree and 5 being strongly agree

I understand how CALC can assist my clients

The content of training was what I expected

The training assisted me in learning

The Presenter kept me engaged in the topic

Training met my needs

The training content will be useful in my work

\begin{tabular}{|c|c|c|c|c|}
\hline $\begin{array}{c}\text { Strongly } \\
\text { Agree }\end{array}$ & Agree & Neutral & Disagree & $\begin{array}{c}\text { Strongly } \\
\text { Disagree }\end{array}$ \\
\hline 4 & 1 & & & \\
\hline 2 & 2 & 1 & & \\
\hline 4 & 1 & & & \\
\hline 3 & 2 & & & \\
\hline 3 & 2 & & & \\
\hline 4 & 1 & & & \\
\hline
\end{tabular}


Australian

National

University
ANU School of Legal Practice

ANU CRICOS Code 00120C

ORCID ID 0000-0002-6371-2975

\begin{tabular}{|l|l|l|l|l|l|}
\hline $\begin{array}{l}\text { Please answer the question on a } \\
\text { scale of } 1 \text { to } 5 \text { with } 1 \text { Not confident2 } \\
\text { somewhat confident } 3 \text { not sure } 4 \\
\text { confident } 5 \text { very confident }\end{array}$ & $\begin{array}{l}\text { Not } \\
\text { Confident }\end{array}$ & $\begin{array}{l}\text { Somewhat } \\
\text { confident }\end{array}$ & $\begin{array}{l}\text { Not } \\
\text { sure }\end{array}$ & Confident & $\begin{array}{c}\text { Very } \\
\text { Confident }\end{array}$ \\
\hline $\begin{array}{l}\text { How confident would feel in } \\
\text { referring to or calling CALC }\end{array}$ & & & & 1 & \\
\hline
\end{tabular}

\section{Suggestions to improve Training}

Continue using real life examples (Only one comment)

\begin{tabular}{|c|c|c|c|c|c|}
\hline $\begin{array}{l}\text { Please rate the quality of the } \\
\text { workshop in skilling you to recognise } \\
\text { and respond to Financial Abuse in } \\
\text { Family Violence }\end{array}$ & Poor & Fair & Good & $\begin{array}{l}\text { Very } \\
\text { Good }\end{array}$ & Excellent \\
\hline Overall content of the course & 0 & 0 & 1 & 5 & 7 \\
\hline Trainers presentation skills & 0 & 0 & 0 & 7 & 6 \\
\hline Participant involvement/grp activities & 0 & 1 & 2 & 4 & 6 \\
\hline
\end{tabular}

This training aimed to improve your knowledge skills and confidence around supporting survivors of family violence to build their financial capability. How would you rate your ability in each of the following topics before and after the training?

\begin{tabular}{|l|c|c|c|c|c|}
\hline $\begin{array}{l}\text { Knowledge to build } \\
\text { financial capability }\end{array}$ & Low=1 & Low=2 & Moderate=3 & Moderate =4 & High =5 \\
\hline Before this training & 2 & 4 & 5 & 2 & 0 \\
\hline After this training & 0 & 0 & 3 & 8 & 2 \\
\hline
\end{tabular}

\begin{tabular}{|l|c|c|c|c|c|}
\hline $\begin{array}{l}\text { Skills to build Financial } \\
\text { capability }\end{array}$ & Low=1 & Low=2 & Moderate=3 & Moderate =4 & High =5 \\
\hline Before this training & 3 & 4 & 4 & 1 & 1 \\
\hline After this training & & & 6 & 5 & 2 \\
\hline
\end{tabular}




\begin{tabular}{|l|c|c|c|c|c|}
\hline $\begin{array}{l}\text { Confidence to build financial } \\
\text { capability }\end{array}$ & Low=1 & Low=2 & Moderate=3 & Moderate =4 & High =5 \\
\hline Before this training & 2 & 5 & 4 & 2 & 0 \\
\hline After this training & 0 & 0 & 5 & 7 & 1 \\
\hline
\end{tabular}

\section{What aspect of workshop did you find the most useful?}

Legal presentation, difference between consumer law and family law, Different organisations supporting the cause, CALC'S presentation, resources, case studies

\section{What aspect of workshop did you find least useful?}

Mostly useful, although presentations \& handouts had too much content, more case studies.

\section{How could workshop be improved?}

Full day training rather than 2 parts, more food, more case studies, more common phrases. Practical and group activities, readable handouts, guest speakers from different organisation, readable handouts. Electronic rather paper based notes wherever possible.

\section{Any feedback on the workshop}

Enjoyable and informative, it was clear that everyone presenting is passionate about their work. Overall great workshop, insightful and would recommend to others to attend. Should be longer to have better networking with the groups 
A colleague, newsletter, email, FC from workplace, worker, online, word of mouth, employer, through sacred heart mission, student placement.

\begin{tabular}{|l|c|}
\hline Engagement with Consumer Action & Responses \\
\hline Before the session had heard of CALC & 12 \\
\hline Before the session had not heard of CALC & 12 \\
\hline I have referred & 4 \\
\hline I have called & 4 \\
\hline I have neither referred nor called & 20 \\
\hline
\end{tabular}

\begin{tabular}{|l|c|c|c|c|c|}
\hline $\begin{array}{l}\text { Please answer the question on a scale } \\
\text { of } 1 \text { to } 5 \text { with } 1 \text { being disagree } 2 \text { being } \\
\text { somewhat Disagree } 3 \text { being neutral } 4 \\
\text { being agree and } 5 \text { being strongly } \\
\text { agree }\end{array}$ & $\begin{array}{c}\text { Strongly } \\
\text { Agree }\end{array}$ & Agree & Neutral & Disagree & $\begin{array}{c}\text { Strongly } \\
\text { Disagree }\end{array}$ \\
\hline $\begin{array}{l}\text { I understand how CALC can assist my } \\
\text { clients }\end{array}$ & 16 & 15 & 1 & & 1 \\
\hline $\begin{array}{l}\text { The content of training was what I } \\
\text { expected }\end{array}$ & 13 & 16 & 5 & & \\
\hline The training assisted me in learning & 23 & 9 & 1 & & \\
\hline $\begin{array}{l}\text { The Presenter kept me engaged in the } \\
\text { topic }\end{array}$ & 23 & 11 & 11 & 2 & \\
\hline Training met my needs & 21 & 12 & 1 & & \\
\hline $\begin{array}{l}\text { The training content will be useful in } \\
\text { my work }\end{array}$ & 21 & & & \\
\hline
\end{tabular}

Please answer the question on a scale of 1 to 5 with 1 Not confident2 somewhat confident 3 not sure 4 confident 5 very confident

\begin{tabular}{|l|c|c|c|c|}
\hline $\begin{array}{c}\text { Not } \\
\text { Confident }\end{array}$ & $\begin{array}{c}\text { Somewhat } \\
\text { Confident }\end{array}$ & $\begin{array}{c}\text { Not } \\
\text { sure }\end{array}$ & Confident & $\begin{array}{c}\text { Very } \\
\text { Confident }\end{array}$ \\
\hline & & & 17 & 16 \\
\hline
\end{tabular}


Comment: The overall data on Consumer Action's training is positive. Most of the data reflects at all training sessions many people had not attended training by Consumer Action before or knew of Consumer Action's work in debt and credit issues and that they could offer legal support for people experiencing family violence or the fall-out from it. This is significant as it means that by virtue of the project's training Consumer Action has reached more services and non-legal professionals and extended its reach to those who support victims of family violence. It also indicates that Consumer Action has conveyed options and the rights of victims of family violence under laws including the Australian Consumer Law and National Credit Code.

Areas for Improvement: Training is effective however; some work may be needed on ensuring the training is engaging and meets the need of participants. This can be difficult if there are a range of participants with different needs. Perhaps checking in with participants early in the training session about what they need and what they would like by way of practical steps might enhance the opportunities. In addition, the feedback from the in-depth interviews about levels of training for different levels of experience and the limited use of legal jargon and practical steps can be taken on board. In addition, asking participants about their work might enable the trainers to adapt their session to the experiences of the people in the room on the day. This accords with good Adult Learning Practice. ${ }^{x x i i}$

What is encouraging are the large numbers of survey participants indicating that they 'Strongly Agree' that the training they have received is relevant and useful.

\section{Consumer Action Law Centre's Systemic Family Violence Work}

A further aim of the project being evaluated is the capacity to ensure that the systemic issues are being addressed by growing an empirical evidence base (through the training and secondary consultation work) to enable Consumer Action to continue to advocate for reform to laws and industry practices that adverse impacts on victims of family violence.

The capacity of community professionals to address systemic issues has been assessed above in the in-depth interviews and appears from this feedback to be in its early stages. In addition to its advice, casework and outreach in relation to family violence related debt matters, Consumer Action has engaged in systemic change by providing input on how the issues under review (from the various policy forums mentioned below) affect people experiencing family violence. Consumer Action has relied on case studies and client stories based in their casework experience, these are often deidentified but in some circumstances with consent and where no safety risks, Consumer Action will use identified while still protecting the community members to provide this input. The author notes that this aligns with the recommendations of the Royal Commission around providing a greater voice for people experiencing family violence and the authors own recommendations about ensuring 
that policy work is informed by those with on-the ground, lived experience. ${ }^{x x x i i i}$ Some of this work is summarised below.

\section{CALC's involvement in the Economic Abuse Reference Group}

Although Consumer Action Law Centre has participated in the Economic Abuse Reference Group (EARG) since approximately mid-2016, with this project's focus its aim is to deepen its input and delve into the implications of family violence related debt and credit, the effects and causes of economic abuse, and the need for regulators and industry and government to improve responses.

Critical to Consumer Action's ability to contribute confidently to the EARG has been the knowledge it has gained through its casework experience with people experiencing family violence. Being able to see a matter through can only in future provide Consumer Action with a greater understanding of the systemic issues of economic abuse highlighted in the Royal Commission.

The Economic Abuse Reference Group is an informal group of community organisations, which influences government and industry responses to the financial impact of family violence. Its members include family violence services, community legal services and financial counselling services (www.earg.org.au). Consumer Action Law Centre has contributed to the EARG's work within its areas of practice - by participating in and hosting quarterly meetings, participating in strategic planning and providing input into submissions and letters. Consumer Affairs Victoria has funded the EARG co-ordinator role.

\section{Work of the Economic Abuse Reference Group}

The different focus areas of the EARG between 2017-2019 were as follows:

- Co-ordinate input into relevant industry codes, guidelines and reviews;

- Contribute to relevant recommendations of the Royal Commission into Family Violence;

- Undertake advocacy to industry and government on behalf of group members to demonstrate the need for process/policy change to improve responses for victim survivors and to influence the change;

- Provide expert input into law reform;

- Support business, government and community responses to family violence by developing/drawing on expertise, resources and training to support best practice;

- Work with stakeholders to monitor and evaluate the impact of the Royal Commission into Family Violence reforms;

- Promote EARG as a source of information for government/industry and a means by which government/industry can source specialist information/input.

Some of the work that the EARG has engaged in during this period is as follows: 
Australian

National

University
ANU School of Legal Practice

ANU CRICOS Code 00120C

ORCID ID 0000-0002-6371-2975

- Development of a Good Practice Guide, referral options and the EARG website

- Development of Issues Papers

- Responding to Legislative Reviews

- Responding to review of industry guidelines

- Engaging the insurance industry, including the Insurance Council of Australia

- Contributions to water sector:

- Implementing Family Violence Policies in the Vic Water Sector

- Proposed changes to the Water Codes

- Contributions to the following banking publications/ documents:

- FOS/ AFCA Approach to Joint Facilities and Family Violence

- ClO Family Violence Guide

- $\quad$ ABA Family Violence Guide - which in turn has resulted in changes to the Banking Code of Practice with explicit reference to family violence

- ANZ Family Violence Guide

- ASIC responsible lending guidance

- Consulting with AFCA about issues of jurisdiction between AFCA and Family Courts re financial abuse debts subject of family law proceedings (happy to explain this further)

- Customer Owned Banking Association Code family violence provisions

- Contributing to the Telecommunication Industry Family Violence Guide- both its initial publication in October 2018 and upcoming consultation in early 2020

- Submission to Australian Law Reform Commission to the Review of the Family Law System

- Energy Code and Guidelines family violence provisions

EARG's voice on financial abuse policy matters is respected within industry, government and the community sector. Many of the recommendations in EARG submissions have been implemented or are part of ongoing reform work. Some of the positive outcomes following EARG involvement are:

- $\quad$ ABA developed the 'Industry Guideline: Financial Abuse and Family and Domestic Violence Policies' document which reflects some of the EARG's recommendations;

- Early commitments in relation to the COBA Code about family violence;

- Family violence is now mentioned in the Insurance Code and the Code includes family violence guidelines for insurers;

- Energy Code changed to refer to family violence, family violence guidelines have been developed;

- Communications Alliance developed the Industry Guideline - Assisting Customers Experiencing Domestic \& Family Violence (2018).

Consumer Action has fed into most of the above activities in multiple ways including through attending EARG meetings (and hosting all meetings), policy submissions and 
consultations for EARG on request, providing case study examples to EARG including examples gleaned from secondary consultations, conducting interviews about our casework with the Project Manager of the EARG, attending meetings with EDR schemes and regulators on behalf of EARG, attending roundtables and events on behalf of EARG and attending stakeholder events.

\section{Other systemic family violence work by CALC}

Contribution to industry codes, guidelines and reviews from time to time in coordination with CALC's policy team, for example (some of the below matters are the same as matters that EARG contributed to):

- Insurance work:

- General Insurance Code - new code obligations and guidance on family violence, including an obligation to have a family violence policy in place by 1 July 2020.

- Contributing to Insurance Council of Australia roundtable on how family violence can interact with wording of policies and payment of claims

- International Organisation for Standardisation standard on Inclusive service: identifying and responding to consumers in vulnerable situations - CALC has a representative on the Australian mirror committee, who provided input on the drafting of the Standard reflecting CALC's family violence casework

- Contribution to the telecommunications family violence guidelines in 2018, and Consumer Action will input into its review in 2020

- Consumer Action is a member of a pilot project which focusses on streamlining requests for removal of default listings on a victim/survivors' credit report where family violence is at play

- Attendance at stakeholder family violence organization events e.g. WIRE financial capability roundtable, WIRE Purse Project launches

- Consumer Action's CEO sits on the expert panel for Monash University's report for ASIC into lending and financial abuse

- Consultation with ASIC about responsible lending guidance

- Consultation with FOS, AFCA, ABA and Customer Owned Banking Association

In April 2017, Consumer Action Law Centre provided case studies (obtained through the project) and questions to be put to banking CEOs as part of the Senate's Review of Australia's Four Major Banks. The banking review was not specific to family violence, however, Consumer Action asked banks to explain why two of their client experiences did not match their express commitment to tackle family violence. This correlates to the feedback from one of the community professionals in the in-depth interview who noted problems at the bank for her client were being actioned by Consumer Action in its policy work with the banks.

In 2018, Consumer Action assisted a victim-survivor of family violence to give evidence at the Financial Services Royal Commission about junk insurance that she was sold on a credit card that she had obtained in circumstances of financial abuse. This client also accompanied 
CALC on a policy and campaigns trip to Canberra to meet with politicians and tell her story to lobby for changes to responsible lending laws.

Consumer Action Law Centre has provided input into the Communication Alliance's review of the Telecommunication Consumer Protection Code and the Telecommunication Industry Ombudsman review. Consumer Action Law Centre's CEO has also raised issues at Telstra's CEO consumer roundtable. CALCs input was focused on changes needed to prevent/interrupt family violence.

On 18 July 2017, Consumer Action Law Centre participated in Consumer Affairs Victoria's forum on economic abuse.

\section{Impact of Policy Work}

Consumer Action has used the case studies and learnings from its trainings and secondary consultations to inform its broader policy and advocacy for reform, including through its work as part of the Economic Abuse Reference Group and participation in various consultations concerning credit and consumer law issues.

As the author has noted in previous reports, systemic change takes time. ${ }^{\text {xxiv }}$

Consumer Action's involvement in policy reforms has been examined and is being assessed for the purposes of this research evaluation. ${ }^{x x v}$ This work aims to improve industry policies and the laws that impact on family violence victims and in addition to the work on policy listed above. The in-depth interviews undertaken for this research and evaluation were designed to measure over time the whether there has been a growth in collaboration, work and impact on family violence with any inroads in the policy area. This is to respond to the Royal Commission call for 'significant research and legislative and policy reform relevant to sexual assault, which has expanded our understanding of and improved our response to family violence ${ }^{\mathrm{xxxvi}}$. Most of the family violence policy work done by Consumer Action has been through its influence as a member of the EARG.

Consumer Action's work on new code obligations and guidance on family violence is a factor in shaping how industry responds to family violence.

However, as noted earlier in the report, in-depth interviewees note that it is up to industry to ensure on the ground front line training of staff and accountability around how they apply the code and interact with people experiencing family violence. It is one thing to have a protocol but another to ensure it is operationalised on the ground in its day to day application.

The key area for improvement by Consumer Action in the interview data is that it needs to improve its feedback loop to people who assist them from other agencies with case studies and other contributions so that they can see the value of the work and also be empowered and invited to participate more. 


\section{Part C Findings, Recommendations and Conclusions}

\section{Findings}

1. The case studies highlight the critical impact of this project and the importance of the interactions on clients, their family members and their professional supporters and trusted intermediaries.

2. Contact with Consumer Action through its secondary consultations have improved decision-making, expanding the repertoire of options for clients and their trusted professional supports.

3. Contact with Consumer Action through its secondary consultations have led to reductions in stress and anxiety and an increase in resilience not only for the client directly but with similar flow on effects for the non-legal professionals.

4. The provision of secondary consultations to non-legal professionals is an efficient use of limited legal resources as for clients downstream the information is used again and again, but, with the professional supports recognising the need to check in a double check advice where situations alter. They also all report the ability to check-in again gives the professional supports greater confidence in giving the assistance around legal options.

5. A minority of participants in the in-depth interviews suggested that at times Consumer Action staff (often identifying newer lawyers) tended to use jargon and the advice was not as tailored/responsive as it might be.

6. Consumer Action's training has reached a wider group of agencies than the base line data indicated in 2017. This is suggestive of the growth in awareness of the Consumer Action offerings, the recognition of the relevance and assistance that consumer laws can offer to people experiencing or escaping family violence in debt and credit matters. In the initial study mainly, financial counsellors were being reached which was natural given the agency's existing previous relationship with financial counsellors. The interviewees and cohort participating in training has been expanded over the last two years of the project to include more counsellors and family violence workers. This building of relationships and trust takes time (as previously indicated given scepticism about the law and role of lawyers) but the data is suggesting Consumer Action is reaching more professional types. This report makes has made some further suggestions around how this can also be improved upon.

7. Consumer Action is actively working in collaboration with networks like the EARG to feed the need for recalibration or changes to law and administration to make a difference to a greater number of people experiencing family violence. The development of guidelines for industry on how to deal with this vexed area of family violence, will affect more people and perhaps lead to earlier intervention and stop problems escalating.

8. Consumer Action's ability to monitor compliance through its increasing engagement with non-legal professionals for a wider range of community agencies enables it to test and verify whether the practice of industry is matching up with industry's stated aspirations. This holding of industry to account and ongoing vigilance, some research participants believe, is keeping industry more honest than they might otherwise be.

9. The data suggests that, over the two years of the project, Consumer Action was inviting more non-legal professionals and clients (with their informed consent) to participate in policy work. This means Consumer Action is enabling a greater voice for 
family violence experts. Participants who had engaged in this work stated it is empowering for all concerned as it gives them a role in the bigger picture and that Consumer Action staff are learning that they need to check in and involve them more than they would previously have done.

10. Participants who are non-legal professionals agreed that greater organisational support and government funding to enable self-care and in recognition of the traumatic nature of the work is critical and that vicarious trauma ought not be managed as an individual's function to be managed, but recognised as a part of the nature of the work with caseworkers given professional development, appropriate debriefing and psychological support, awareness of different experience levels and a mix of work.

\section{Recommendations}

1. Induction of new staff into how to interact with clients and non-lawyers, communication and interpersonal skills and cultural competency and ways of working in collaboration and mutual respect for the different skills sets and offerings of all the professionals needs to be a part of the organisational process.

2. Ongoing legal staff professional development is critical and learning about ways to interact and not interact with non-legal professionals and knowledge around broad impact of family violence, disadvantage and trauma need to shape and inform practice.

3. Graduated training for non-legal professionals might be considered so that people with who are new are differentiated from those with more years of experience, so this is recognised.

4. A feedback loop and invitation to non-legal professionals seeking their input and collaboration in policy work and developments and impacts of this work was requested by all interview participants.

5. Most participants in the in-depth interviews said the training was great and generally delivered in a way that was useable and relatable. Two participants added that in training, lawyers need to deliver materials using best community development and adult learning practice. Lecture format may suit lawyers but is not necessarily tailored to what professionals need.

6. All participants called for vigilance so that training was a genuine reciprocal respect and understanding of the value of what all professionals have to offer. This is critical to trust and mutual respect and reciprocity and is preferred to situating law and lawyers at the top of any hierarchy. The lower levels of referrals out to non-legal agencies may need to also be a focus for Consumer Action moving forward and will demonstrate levels of holistic responses to these complex and inter-related issues clients face beyond merely a focus on referrals to the lawyers.

\section{Conclusions}

The data is clear on the immense value of secondary consultations and their ability to enable quick, efficient, practical on the spot advice or where it is more complex the responsiveness of the service and its expertise. 
The data also suggests that it is not only the legal information and advice that is provided that has made a difference but sometimes, client outcomes and systems reform are made possible through Consumer Actions linkages. These extend directly with senior levels in relevant industry or the regulators that can lead to results where traditional approaches meet with resistance. These linkages that Consumer Action has established, were seen as adding a valuable level to ensuring interventions can happen when bureaucracy can sometimes hinder the need to respond more immediately to clients who face a range of problems from family violence.

The Consumer Action Family Violence project has been lauded by research participants as of immense assistance.

Identified in the data is the additional incomes support outcomes that give people experiencing family violence and their children more income. This has ensured they are able to: pay the rent, buy food and keep a car (to escape, feel safe and commute sometimes long distances in rural areas or to ferry children around) and keep medical appointments, pay for pharmaceutical and other health needs and pay so-called 'voluntary' school fees (to prevent feeling of child exclusion that can result).

The information provided benefits not just the initial client but has been used to benefit many clients downstream.

One participant indicated sometimes they and their team use the secondary consultation information to assist a further 20 or more clients. This is clearly extending the remit of stretched legal assistance services, but all participants were clear that secondary consultation were only of value if done well and in a way that is practical and tailored to clients and their trusted intermediaries. ${ }^{\text {xxvii }}$

The Consumer Action Family Violence project's secondary consultations were seen as critical by all participants in the in-depth interviews and in the aggregated service data.

Recounted in the qualitative data was the need for traumatised and overstretched clients (who are often in a state of high anxiety and fear about their debts and threats of their former partner) to have access to secondary consultations as they can ill afford further delay or to wait until the conclusion of family law cases to access extra income.

Most participants stated secondary consultations obviated the need for clients having to retell their stories over and over. All interview participants noted clients may be reticent to speak lawyers too, given poor stereotypes and experiences with lawyers and the law previously. Most participants noted that their experience through the project had increased their trust in lawyers. Also, sometimes the mention of the Consumer Action lawyers over time to their clients, and the help and direction being offered by Consumer Action, was also serving to break down poor negative stereotypes of lawyers and the law in clients. A few participants noted over time initial resistance by clients to liaise directly with Consumer Action had 
dissipated due to the lawyers' interactions with their 'trusted intermediary.' This is suggestive that lawyers interpersonal and communication skills and reliability and helpfulness may be 'rubbing off' to reassure clients and perhaps reappraise their view of what lawyers are like?

Consumer Action's role is critical in the policy area. It is playing a crucial role in monitoring whether industry is in fact complying with the law and their own codes in the actual way they operate.

There is some slippage being reported in the responsiveness of some industries with the four main banks, insurance, car dealerships and utilities being identified in how they manage claims involving victims of family violence. Two participants said industry on the ground staff used the term 'compassion fatigue' and in another instance used the term 'drama queen' in relation to clients raising their family violence issues. Consumer Action through its case work and work with non-legal professionals can have its 'ear to the ground' and is able to identify poor practice and non-compliance with the laws, codes of practice and industry protocols.

Because of its connection to lived experience and reports to it through its expanding relationship with community agencies, Consumer Action is increasingly better able to ensure accountability and responsiveness of industry and regulators. This is suggestive of the fact that Consumer Action is playing a pivotal role in informing industry of lived experience and barriers and impediments in practice that need to be overcome and reforms that can address this formulated not just by Consumer Action but with other non-legal professional experts and client voice, that Consumer Action has facilitated over the past two years. 
Appendix 1 Training Materials Examples

\subsection{Family Violence Issue Spotting}

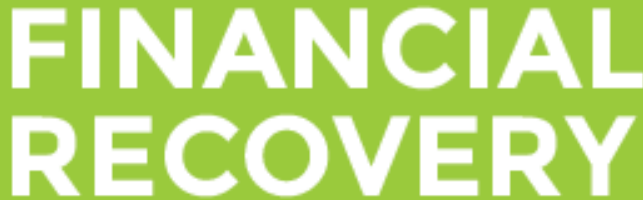

A guide to helping people who have experienced family violence



Cripping debt Is your client struggling with debts that they can't keep up with anymore?

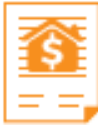

Joint debt

Was your client pressured into signing up to a joint loan with their partner that they didn't want or even benefit from?

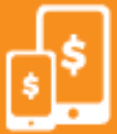

Phone contracts

Was your client pressured into entering a phone contract for their partner's benefit?



Poor credit history

Does your client's credit report have old or incorrect listings on it?

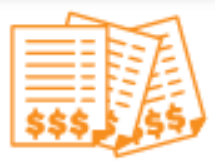

Joint bills

Has your client been left with unaffordable telco and utility bills after the breakdown of their relationship?

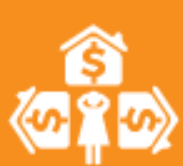

Unaffordable loans Was your client signed up to a loan that they could never have afforded in the first place or a loan that wasn't what they asked for?
As your client starts rebuilding a life for themselves, there are a range of financial issues which they might be faced with

There are certain protections in the consumer and credit law system which your client may be able to rely on.

Call our Worker Advice Line to find out more.

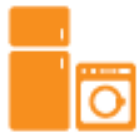

\section{Consumer Leases} or Rent-to-Buy

Is your client paying expensive rent for essential household goods? Are they paying through their Centrepay?

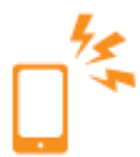

Debt collectors

Is your client being harassed on the phone by debt collectors?

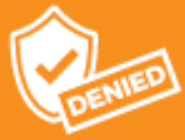

Insurance

Is your client being denied cover under their insurance policy?

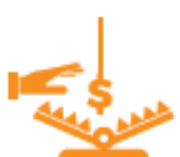

Payday Loans

Pawnbroking

Has your client pawned some of their belongings to a pawnbroker?
Has your client taken out small loans with high interest and fees? 


\subsection{Who's Who Referral Agencies}

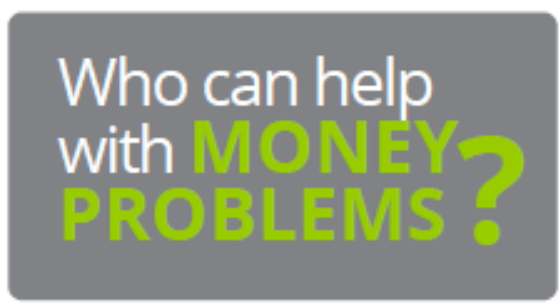

Access to Funds
(NILS)
Up to $\$ 1500$ no interest loans
for essential goods \& services
(not housing costs) 136457

Financial Literacy
Women talk money
program - video resources
1300134130



\section{Financial Counsellors}

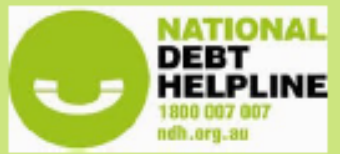

NEVER PAY for 'Credit repair'

and 'debt negotiators'

\section{Infringements}

Search for fines at

httpsa//online.fines.vic.gov.au/

Free Legal Services

Victoria Legal Aid and Federation of Community Legal Centres

For Aboriginal cilents, Sheriff's Aboriginal Liaison Officers(SALOs) can help you resolve your fines and warrants. Contact your local

Aboriginal Co-op or local justice and Community Safety Office.

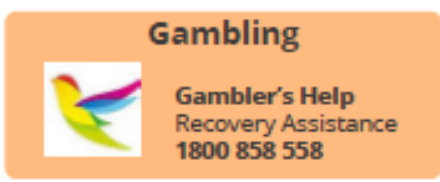

\section{Child Support Legal Service}

Victoria Legal Aid run a rotating legal service for Child Support places fill quickly.

See website for times and locations

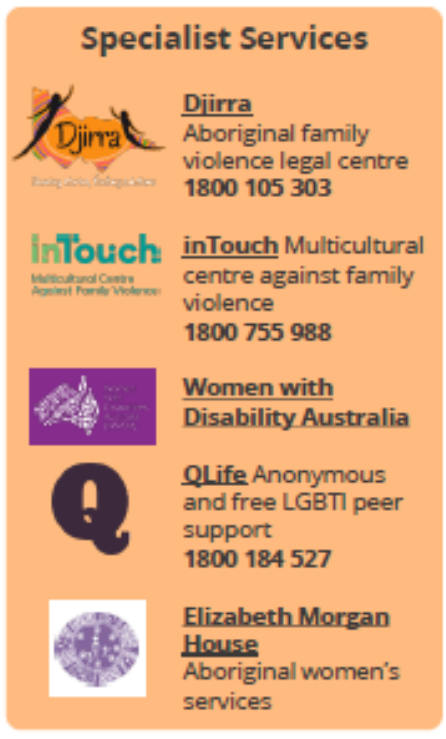

\section{Bankruptcy}

Speak to a Financial Counsellor

Application kit - AFSA Website

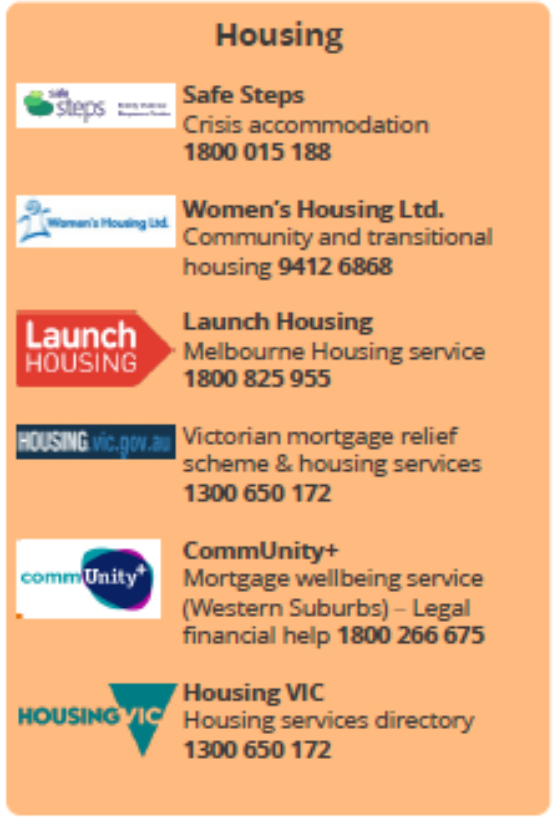

\section{CareRing}

A Klldonan Uniting Care support service for customers ANZ, Jemena, NAB, Origin, Western Water or Yarra Valley Water experiencing hardship

1800545366

or email CareRing@kildonan.org.au

Utility Relief Grants
Speak with energy provider first

\begin{tabular}{|c|c|}
\hline \multicolumn{2}{|c|}{ Free Legal Services } \\
\hline $\begin{array}{l}\text { tsumer } \\
\text { tion }\end{array}$ & $\begin{array}{l}\text { Consumer Action Law Centre } \\
\text { Financial issues. } \\
\text { Worker line: } 96023326\end{array}$ \\
\hline & $\begin{array}{l}\text { Women's Legal Service } \\
\text { Victoria } \\
\text { Family law issues } \\
1800133302\end{array}$ \\
\hline & $\begin{array}{l}\text { Tenants Union of Victoria Ltd. } \\
\text { Renting issues } \\
94162577\end{array}$ \\
\hline SSR S & $\begin{array}{l}\text { Social Security Rights } \\
\text { Victoria Inc. } \\
\text { c.Centrelink issues } \\
1800094164\end{array}$ \\
\hline & $\begin{array}{l}\text { Victoria Legal Aid } \\
\text { Fines \& justice system issues } \\
1300792387\end{array}$ \\
\hline Ration & $\begin{array}{l}\text { Federation of Community } \\
\text { Legal Centres Victoria } \\
\text { Find a community legal service } \\
96521500\end{array}$ \\
\hline
\end{tabular}




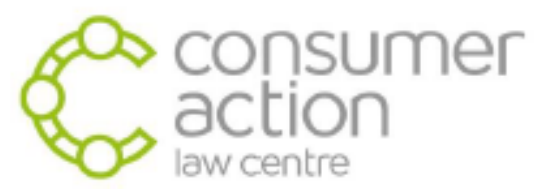

Debt and Family Violence - Practice Note 2018

\section{Finance Contracts}

\section{Complaints Process}

Standard process for complaints against finance providers
1. Request documents and temporary hold from lender - Iemplate letter
2. If not provided - complain to Ombudsman - there are fast track processes for document
requests
3. Identify a potential cause of action and write letter of demand - speak to Consumer
Action who can provide a precedent letter
4. If poor response or no response - complain to Ombudsman

IMPORTANT: If repossession is imminent or creditor has commenced legal proceedings then skip straight to Step 4 as the Ombudsman rules provide that the credit provider must cease enforcement action once there is an open Ombudsman complaint against them.

\section{Joint debts \& the law}

The Banking Code of Practice is an optional industry code. It sets a standard in relation to joint debts that banks who have signed up to it must follow (it forms part of the contract with their customer). Because it is considered best practice it is also persuasive for lenders who have not signed it.

Banking Code of Practice on Joint Debts

29.1. We will not accept you as a co-debtor under a credit facility where it is clear, on the facts known to us, that you will not receive a benefit under the facility.

29.2. We will, before signing you up as a co-debtor, take all reasonable steps to ensure that you understand that you may be liable for the full amount of the debt and what your rights are under clause 29.3.

29.3. If you are jointly and severally liable under a credit facility, we will allow you to terminate your liability in respect of future advances or financial accommodation on giving us written notice. This right only applies where we can terminate any obligation we have to provide further credit to any other debtor under the same credit facility 


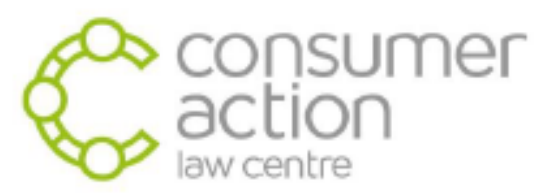

How do I know if the lender a signatory to the Banking Code of Practice?

There is a list of signatories here:

https://www.ausbanking_org.au/Industry-Standards/ABAs-Code-of-Banking-Practice/Banks-thathave-adopted-versions-of-the-Code-of-Banking-Practice

The lender is not a signatory, now what?

If the lender is not a signatory, you can still rely on the Code as good industry practice under the Ombudsmen's rules:

- See: FOS terms of Reference (clause 8.2) httros://www fos,org.au/public/download lisp?id=4040

- See: CIO Rules (Paragraph 12) https://www.cio.org.au/assets/27886963/Cl0\%20Rules\%2010th\%20Edition\%20\%20August $\% 202016 \% 20 \% 282 \% 29 \% 281 \% 29$ ndf

\section{Responsible Lending}

The law in relation to responsible lending applies to all borrowers (unless the loan was for business purposes). It can be an easier claim to make out than some of the other claims mentioned here.

Responsible Lending -Sections 128-133 of the National Consumer Credit Protection Act In summary, lenders are required to:

1. make reasonable inquiries about the consumer's:

- financial situation, and

- requirements and objectives

2. take reasonable steps to verify the consumer's financial situation; and

3. make a final assessment about whether the credit contract or consumer lease is 'not unsuitable' for the consumer (based on the inquiries and information obtained in the first two steps).

How are the Responsible Lending Laws applied?

- The Australian Securities and Investment Commission created Regulatory Guide 209 to explain responsible lending obligations to lenders. It is a helpful resource in interpreting and applying the law.

- In 2018 the Royal Commission into Banking Services created an overview document which is very readable and explains the Responsible lending laws: Background Paper 4: Everydav Consumer Credit-Overview of Australian Law Regulating Consumer Home Loans, Credit Cards and Car Loans 


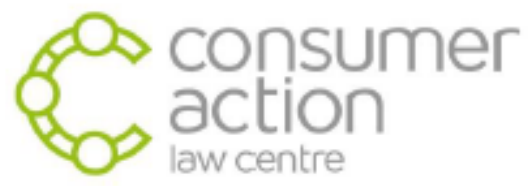

Calculating Loss for Responsible Lending

Calculating loss from responsible lending breaches can be quite difficult. The Financial Ombudsman Service and the Credit and Investments Ombudsman have released guides about how they assess loss in determining disputes:

Financial Ombudsman Service approach to Responsible Lending

Credit and Investments Ombudsman Position Statement 5: Responsible Lending

\section{Pressured into Loan ---}

\section{Standards for lenders in identifying and responding to family violence}

Sometimes your client may have been pressured into a contract by her partner and be seeking to be released from the contract. It is difficult for the client to be released based on this pressure alone unless it can be shown that the lender was on notice of the family violence and failed to act to avoid it tainting the transaction. The cause of action would likely be unconscionability or unjust transaction under section 76 of the National Credit Code.

Following the Royal Commission into Family Violence the Australian Bankers Association, Financial Ombudsman Service and the Credit and Investments Ombudsman created guidelines about what they expected from their members in relation to identifying family violence.

- Australian Bankers Association: Financial Abuse and Family and Domestic Violence Policy-- Family Violence guideline

- Credit and Investments Ombudsman Position Statement 10 - Family violence

- Financial Ombudsman Service: FOS approach to Joint Facilities and Family violence

\section{Negotiating -- Policy and Public Relations}

Some of the banks have gone further than others in publicly addressing family violence. These banks have published information on their views and approach to Family Violence. It can be worth investigating a company's public statements when negotiating.

Warning: This Practice Note is intended as a guide to the law and should not be used as a substitute for legal advice. This information applies only in Victoria and reflects the law as at 18 April 2018. 


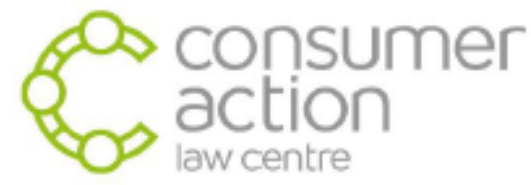

\section{Phone contracts}

Unfortunately, there are fewer consumer protections for phone contracts than there are for finance contracts. The Telecommunications Consumer Protection Code provides some protections. The most common complaint that we see is in relation to women signing phone contracts for their partner and then being left with the debt when they separate.

6.2 Responsible provision of Telecommunications Products

Suppliers must undertake a Credit Assessment before providing a PostPaid Service to a Consumer and explain the financial implications of the provision of that Post-Paid Service to a Customer or their Guarantor.

6.2.1 A Supplier must take the following actions to enable this outcome:

(a) Assess credit risk: undertake a Credit Assessment;

(b) Advising the Customer about liability: where the Supplier is made aware by the Customer that the Customer is not going to be the principal end user of the Telecommunications Service, inform the Customer at the time it becomes aware (or as soon as practicable thereafter), that the Customer remains liable for the use of the Telecommunications Service;

(c) Requiring a Guarantee: if a Supplier requires a Guarantee the Supplier must provide advice to the Guarantor regarding the nature and effect of the Guarantee before the Guarantee is provided by the Guarantor and the Telecommunications Product is provided by the Supplier; and (d) Cooling off period for Guarantor: provide a Guarantor with a minimum 10 Working Days cooling off period in which the Guarantor may terminate the agreement for which the Guarantee is provided.

\section{http://www.commsalliance.com.au/Documents/all/codes/c628}

See also: TIO Position Statement - assessment for credit for a service

Complaints about phone companies can be lodged with the Telecommunications Industry Ombudsman (TIO). In 2016-17 the TIO received 158,016 complaints $(76,650$ of those were against Telstra). $90 \%$ of complaints do not continue beyond being referred to the phone provider. ${ }^{1}$

For more information on the TIO's Complaints process: $\underline{\text { TIO Review Factsheet }}$

Warning: This Practice Note is intended as a guide to the law and should not be used as a substitute for legal advice. This information applies only in Victoria and reflects the law as at 18 April 2018.

\footnotetext{
${ }^{1}$ https://www.tio.com.au/_data/assets/pdf_file/0005/253643/2017_0929-TIO-Report-Final.pdf 


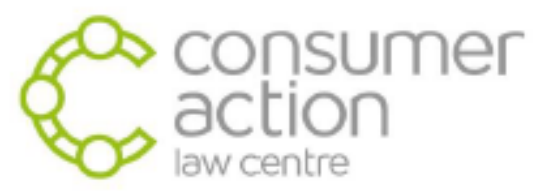

\section{Energy and Water Debts}

Yarra Valley Water has led the charge for greater awareness of family violence within the utility sector. The other utility providers are catching up. The Energy and Water Ombudsman have released a guide: Position Statement 7 - Family Violence

EWOV have addressed the effect of privacy breaches on people who have experienced family violence: see Case Study

- Breach of Privacy -- https://www.ewov.com.au/resources/case-studies/failure-tocorrectly-update-the-details-of-a-victim-of-family-violence-leads

Financial Hardship

Often the main Issue with Energy and Water bills is simply that they are unaffordable. Financial counsellors are experts at dealing with these kinds of debts. You can find face to face financial counsellors on the Financial Counselling Australia website or by calling the National Debt Helpline on 1800007007.

Utility Relief Grants can provide some temporary relief as well.

Warning: This Practice Note is intended as a guide to the law and should not be used as a substitute for legal advice. This information applies only in Victoria and reflects the law as at 18 April 2018. 


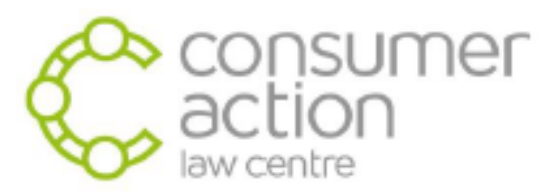

\section{Credit Reporting}

Credit Reporting law is complex and often difficult to follow. Do not use Credit Repair Agencies!

Credit Reporting Law

There are three main sources of law and rules:

- Part IIIA Privacy Act 1988 (Cth)

- Privacy Regulations 2013 (Cth)

- Credit Reporting Code 2014

All accessible from the Office of the Australian Information Commissioner's website

Helpful guides on Consumer Action Law Centre's Website

- How can I get a Free copy of my credit Report?

- Can I clear my credit report?

- $\underline{\text { Tips and templates for statute barred debts }}$

The OAIC's privacy fact sheet series are also useful.

Summary of Ombudsmen's guide to Family Violence

Credit and Investment Ombudsman's Position Statement 10 - Family violence

4.14 Where the consumer is not liable for any part of the overdue amount that has been listed on their credit file, correcting the default information will involve destroying the default information.

4.15 Under para 20.5 of the CR Code, a credit reporting body may be required to destroy default information about the consumer if:

- the consumer enters into a payment arrangement or a refinance or the debt is paid, settled or waived \&

- the payment was overdue because of circumstances beyond the consumer's control.

4.16 A victim of family violence may have been default listed because of circumstances beyond their control. They may be sleeping in a car, on a friend's couch or in a refuge, so they do not have a permanent address. They will not receive notices the FSP sends to the consumer's last known address.

Financial Ombudsman Service: FOS approach to Joint Facilities and Family violence

2.7 If an FSP is on notice that a borrower is experiencing family violence The FSP should not default list the borrower. If an FSP is unaware family violence is or was present until after a default listing is made... we consider it to be good industry practice for the FSP to remove the listing.

Where a customer entered into a loan because they were subject to duress and received no benefit from the funds, and the FSP was or should have been aware of this at the time of lending, then the FSP should release the customer from liability under the loan and remove any adverse credit information related to the debt. 
1.4 Family Violence Consumer Action Training Slides 2019

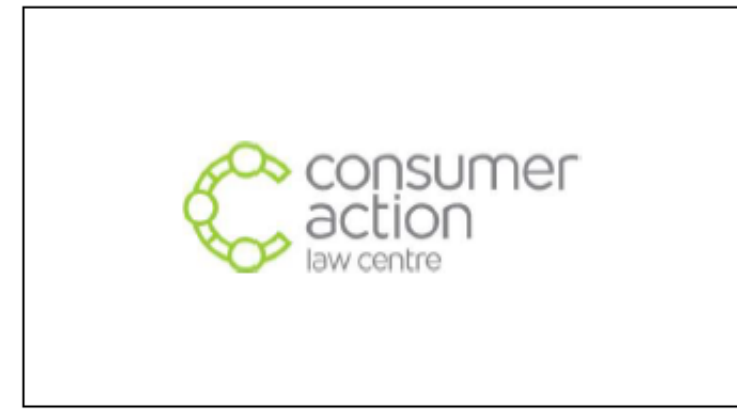

1

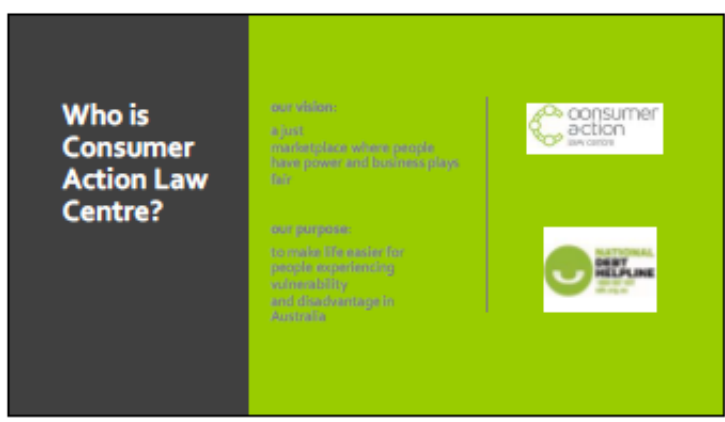

Financial abuse...

'a perpetrator's 'controlling and humiliating behaviours that constrain a woman's ability to 'acquire, use and maintain (financial) resources, thus threatening her economic security and potential for self-sufficiency'

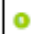

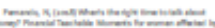

5



2
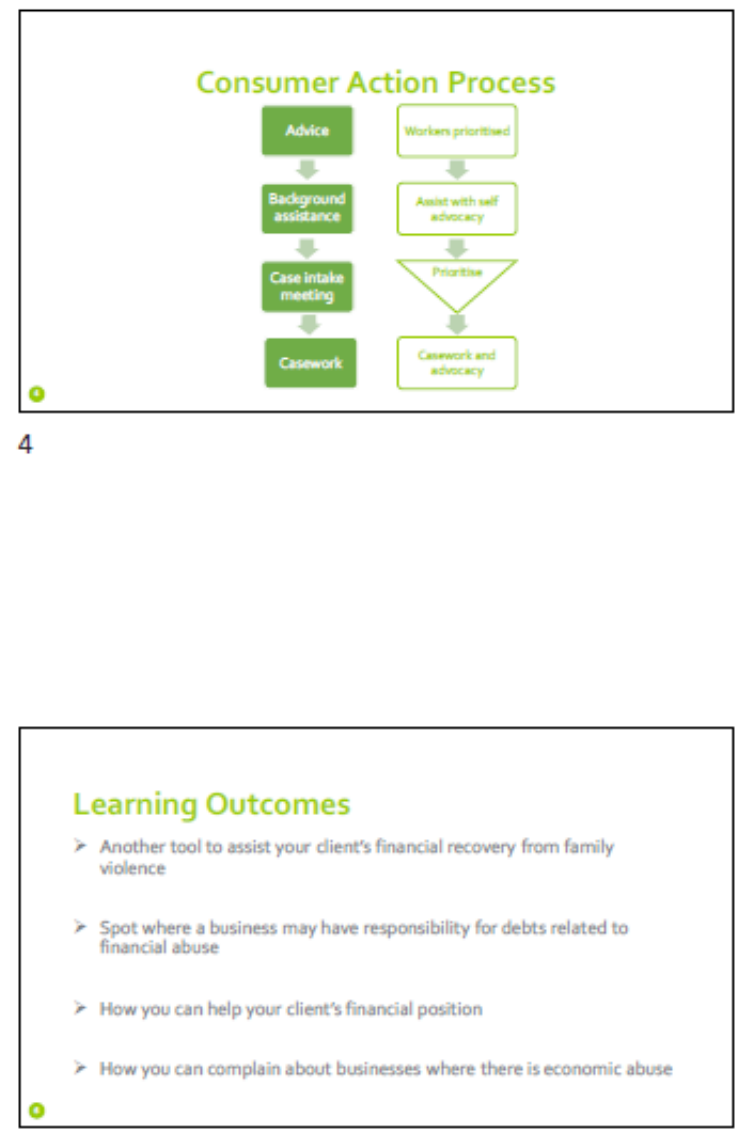

6 


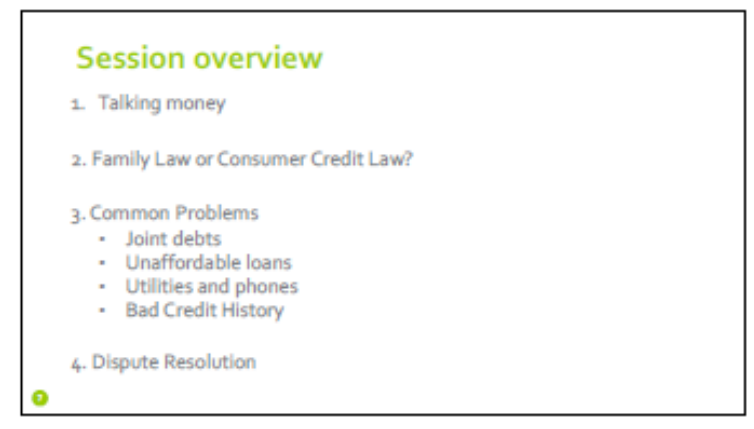

7

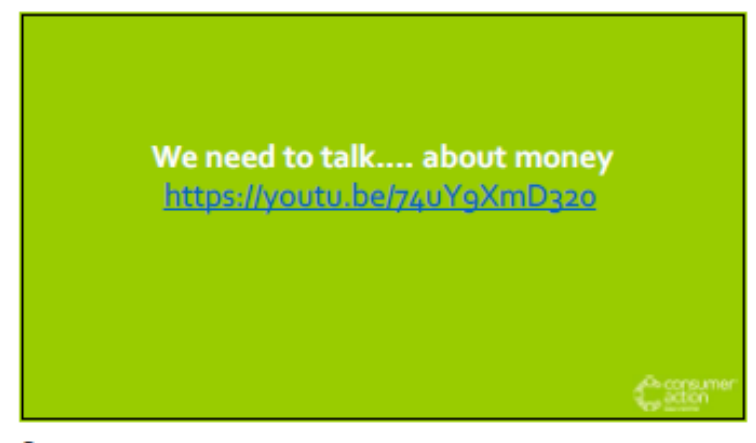

8

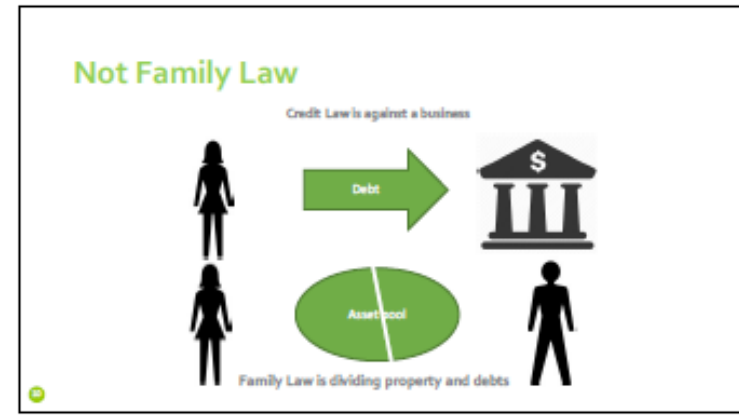

10

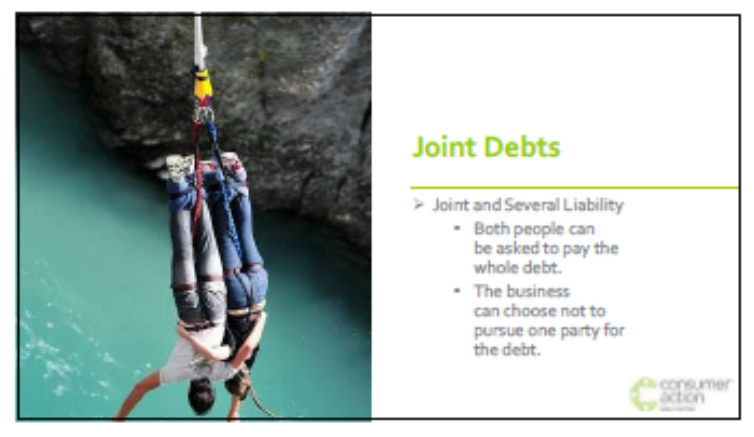

12 


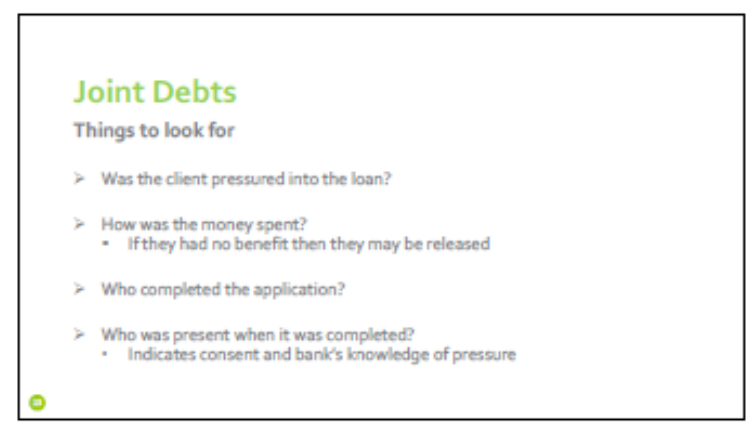

13

Unaffordable or unsuitable loans

Things to look for

$>$ Was it affordable at the time of application

D. Why did they borrow the money?

$>$ How was the money used?

Did they get more money than requested?

D. What did the bank knowlask for?

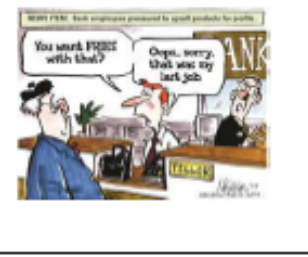

15

Utilities and phones

Things to remember

7. Phones - unaffordable,

$>$ Did they benefit from sevice?

> Changing names on the bill

is Access to personal information

$>$ Poor complaints handling
processes

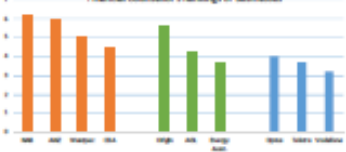

17

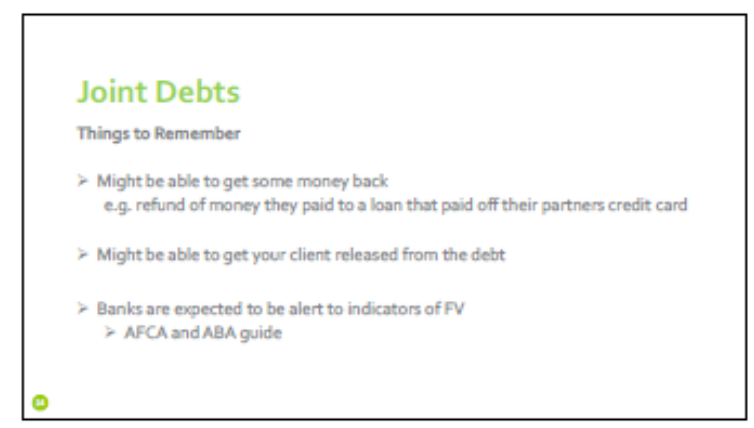

14

Unaffordable or unsuitable loans

Things to Remember

- May relieve client from the fees and interest

- In most cases will need to pay back any money they received - no free money.

it It may not be a helpful resolution depending on client's circurnstances.

Utilities and phones

Things to remember

Client can close accounts - be mindful of termination fees

7 Complain to the no, EWov

- Complain about privacy breaches

- Financial Counsellors are experts in these matters

$>$ Reform is needed

> NEW Payment Difficulty Framework can assist clients in hardship:



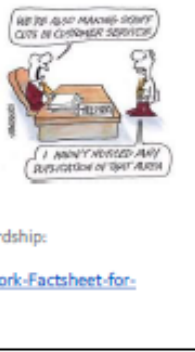

18 


\section{$*$ Australian \\ National \\ University}

ANU School of Legal Practice

ANU CRICOS Code 00120C

ORCID ID 0000-0002-6371-2975

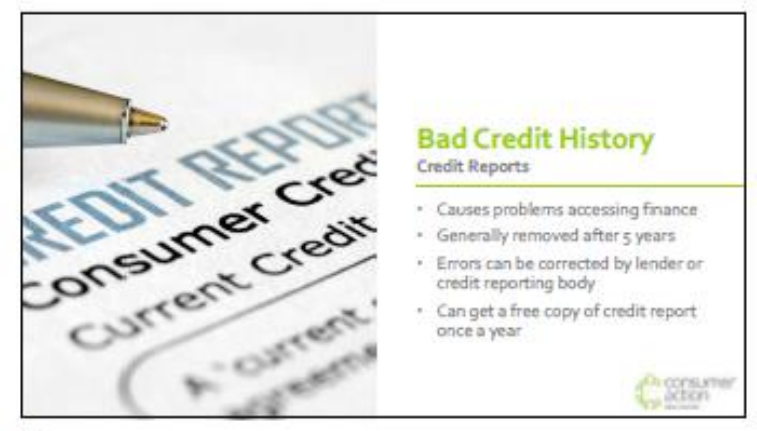

19

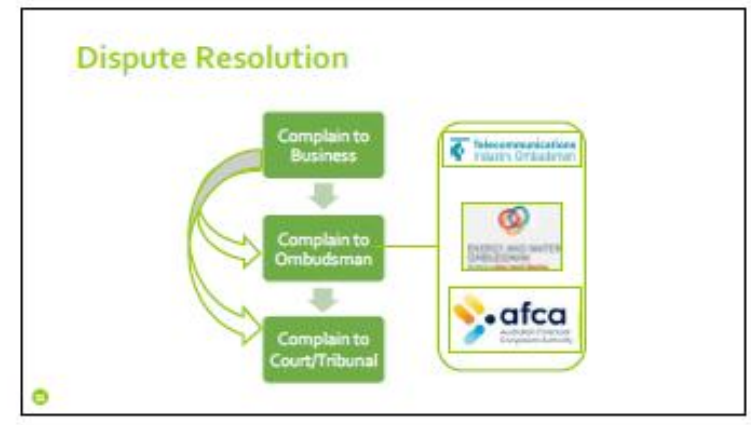

21

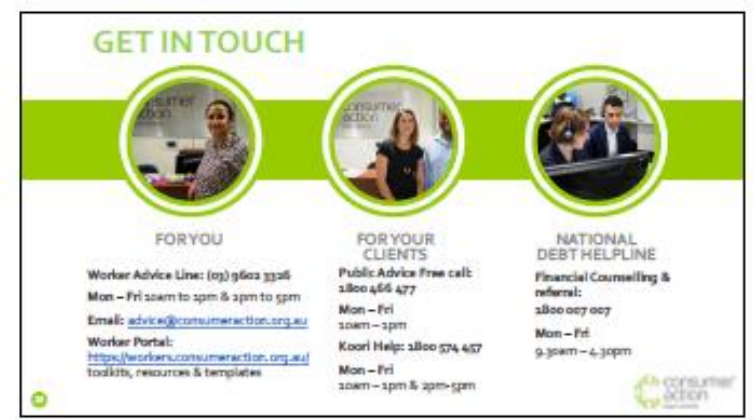

23

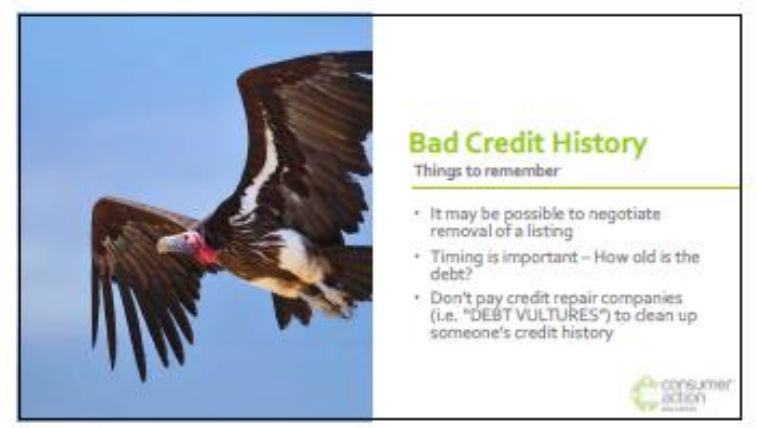

20

\section{Session review}

- Credit Law is against business, Family Law is dividing property

- Joint debts - may be released if for partners benefit only

> Unaffordable loans - often only relieved of fees and interest

- Utilities and phones - contact us if you receive a poor response

7 "Bad" Credit History-debt vultures are bad

> Dispute Resolution - ombudsman can help

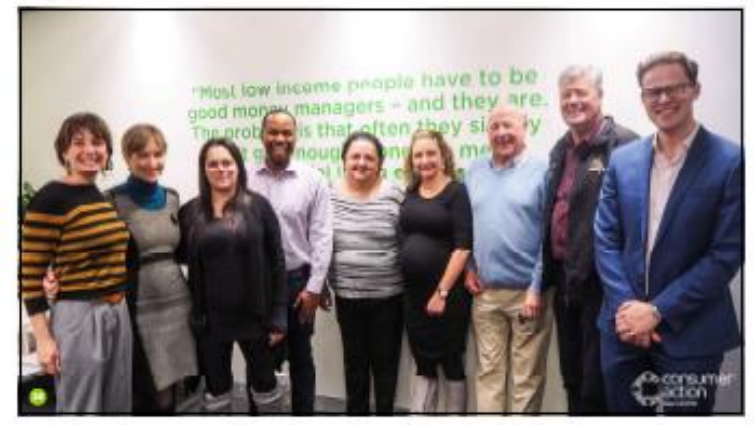


ANU School of Legal Practice

Australian

ANU CRICOS Code 00120C

National

ORCID ID 0000-0002-6371-2975 


\begin{abstract}
'This is a service project supported by the Victorian Government's Department of Justice \& Regulation through a funding grant, 2016 -2017. This independent research was provided pro bono by ANU and Dr Liz Curran. The service project's title has been changed to reflect that it involves service providers who have professional ethical obligations and are 'professionals' recognising this adds dimensions that the term 'worker' does not encapsulate.

ii The Report of the Royal Commission into Family Violence (Victoria) See pages 76 and 108. http://www.rcfv.com.au/Report-Recommendations accessed 21 September 2017.

iii Curran L 'Lawyer Secondary Consultations: improving access to justice and human rights: reaching clients otherwise excluded through professional support in a multi-disciplinary practice' 8(1) Journal of Social Inclusion (2017)

https://josi.journals.griffith.edu.au/index.php/inclusion/article/view/817.

iv $\mathrm{Dr}$ Curran, in her research evaluations has defined legal secondary consultation as: where a lawyer offers a community worker (such as a doctor, nurse, youth worker, social worker or financial counsellor) legal advice or information on legal processes (such as what happens at court, and how to give evidence or structure reports for a court to provide the required considerations), or on their professional and ethical obligations, or guides the community worker through tricky situations involving their client or their work for clients. See Curran L, 'Lawyer Secondary Consultations: improving access to justice and human rights: reaching clients otherwise excluded through professional support in a multi-disciplinary practice' 8(1) Journal of Social Inclusion (2017) https://josi.journals.griffith.edu.au/index.php/inclusion/article/view/817.

` See for example, Curran L, 'Final Evaluation Report for the Legal Services Board Victoria - 'Why Didn't You Ask?' - Evaluation of the Family Violence Project of the Loddon Campaspe Community Legal Centre' (April 16, 2015). https://ssrn.com/abstract=2631378 or http://dx.doi.org/10.2139/ssrn.2631378
\end{abstract}

vi Curran L, 'Sharing elements of effective practice to address earlier, signs of family violence' (2019) 44 (3) Alternative Law Journal, https://doi.org/10.1177/1037969X19843624

vii The World Health Organisation defines the social determinants of health (SDH) are 'the conditions in which people are born, grow, live, work and age. These circumstances are shaped by the distribution of money, power and resources at global, national and local levels. 'World Health Organisation Social Determinants of Health', World Health Organisation (Web Page)

$<$ https://www.who.int/social_determinants/sdh_definition/en/>.

viii The Report of the Royal Commission into Family Violence (Victoria) Vol. IV,103, Vol. VI, 118, Vol IV, 102-106. http://www.rcfv.com.au/Report-Recommendations, accessed 21 September 2017 ${ }^{i x}$ See for example, Smallwood E, Stepping Stones: Legal barriers to economic equality after family violence, Women's Legal Service Victoria and the Legal Services Board and Commissioner of Victoria (2016). http://www.womenslegal.org.au/files/file/Stepping\%20Stones\%20Report(1).pdf accessed 18 November 2017. x Also, a point made by women interviewed about their experiences in Neilson C and Renou B, Will Somebody Listen to Me, Loddon Campaspe Community Legal Centre and the Legal Services Board and Commissioner of Victoria (2015). http://lcclc.org.au/2015/05/family-violence-report/ accessed 18 November 2017.

xi Victorian Government, Department of Justice and Regulation, Access to Justice Review, 4 October 2016, Available at https://engage.vic.gov.au/accesstojustice; Pleasence P, Coumarelos C, Forell S \& McDonald HM, Planning legal outreach, (Law and Justice Foundation of NSW, Sydney) (2015)

http://www.lawfoundation.net.au/ljf/site/templates/UpdatingJustice/\$file/UJ_45_Planning_legal_outreach_FI NAL.pdf ; Coumarelos C, Macourt D, People J, Mcdonald HM, Z, Iriana R and Ramsey S, (2012)'Access to Justice and Legal Needs Legal Australia-Wide survey: legal need in Australia' (New South Wales Law and Justice Foundation, Sydney) http://www.lawfoundation.net.au/ljf/site/templates/LAW_AUS/\$̧file/LAW_Survey_Australia.pdf; Allen Consulting Group. (2014) Review of the National Partnership Agreement on Legal Assistance Services, Final Report, June (Melbourne, Australia, The Allen Consulting Group). http://www.acilallen.com.au/cms files/NPA\%20Review LAS\%20report final.pdf; Australian Government Productivity Commission Final Report, 'Access to Justice Arrangements, No 72, September 2014, http://www.pc.gov.au/inquiries/completed/access-justice/report; Curran L, 'Ensuring Justice and Enhancing Human Rights: A Report on Improving Legal Aid Service Delivery to Reach Vulnerable and Disadvantaged 
People, La Trobe University \& Victoria Law Foundation (2007) https://libertyvictoria.org.au/sites/default/files/Report\%20-

\%20Ensuring\%20Justice\%20and\%20Enhancing\%20Human\%20Rights.pdf All accessed 18 November 2017.

xiii Smallwood E, Stepping Stones: Legal barriers to economic equality after family violence, Women's Legal Service Victoria and the Legal Services Board and Commissioner of Victoria (2016).

http://www.womenslegal.org.au/files/file/Stepping\%20Stones\%20Report(1).pdf accessed 18 November 2017 xiv Curran L, 'Lawyer Secondary Consultations: improving access to justice and human rights: reaching clients otherwise excluded through professional support in a multi-disciplinary practice' 8(1) Journal of Social Inclusion (2017) 45-77 at 48.https://josi.journals.griffith.edu.au/index.php/inclusion/article/view/817 ${ }^{x v}$ Curran L, 'Multi-disciplinary Practice Health Justice Partnerships-Working ethically to ensure reach to the most in need', 26 Nottingham Law Journal (2017) 11 -36; Mark F Harris, Jenny Advocat, Benjamin F Crabtree, Jean-Frederic Levesque, William L Miller, Jane M Gunn, William Hogg, Cathie M Scott, Sabrina M Chase, Lisa Halma, and Grant M Russell, 'Inter-professional teamwork innovations for primary health care practices and practitioners: evidence from a comparison of reform in three countries' (2016) $9 \mathrm{~J}$ Multidiscip Health, 35-46; Tobin-Tyler E., Anderson, L., Rappaport, L., Shah, A., Edberg, D., Paul E. 'Medical-Legal Partnership in Medical Education: Pathways \& Opportunities Journal of Legal Medicine'. 2014; 35 (1): 149-177; Lawton, E., TobinTyler, E. 'Optimizing the Health Impacts of Civil Legal Aid Interventions: The Public Health Framework of Medical-Legal Partnerships' Rhode Island Medical Journal. 2013; 96 (7): 22-26; Tobin-Tyler, E. 'Allies Not Adversaries: Teaching Collaboration to the Next Generation of Doctors and Lawyers to Address Social Inequality' Journal of Health Care Law and Policy. 2008; 11: 249-294; Crockett A and Curran L, 'Measuring the impact, quality and effectiveness of legal assistance services in a climate of reduced funding and increased government expectations: The Australian experience' 22 (3), (2016), European Journal of Current Legal Issues http://webjcli.org/article/view/468; Curran, Liz, A Research and Evaluation Report for the Bendigo HealthJustice Partnership: A Partnership between Loddon Campaspe Community Legal Centre and Bendigo Community Health Services, October 2016 By Dr Liz Curran, Australian National University 'I Sleep Better at Night'. (Interview with Client) Published 22 November 2017 (October 31, 2016). Available at SSRN:

https://ssrn.com/abstract=; Curran L 'Improving access to justice through multi-disciplinary practices': Health Justice Partnerships' 22 November 2016, Nottingham Trent University. See podcast http://www.nlscle.org.uk/improving-access-justice-health-justice-partnerships/ and http://www4.ntu.ac.uk/apps/events/15/home.aspx/event/189681/default/seminar_by_visiting_scholar_liz_c urran;

xvi Curran L, 'Sharing elements of effective practice to address earlier, signs of family violence' (2019) 44 (3) Alternative Law Journal, https://doi.org/10.1177/1037969X19843624.

xvii Neilsen K and Maraglia M (2017) 'What works for whom in which circumstances? On the need to move beyond the 'what works?' question in organizational intervention research' 70 (1) Human Relations 40-62 https://doi.org/10.1177/0018726716670226

\footnotetext{
xviii Leering M, 'Conceptualizing Reflective Practice for Legal Professionals' (2014) 23 Journal of Law and Social Policy, 83-106.

xix Dick B, 'Action Research and Action Learning for Community and Organisational Change' http://www.aral.com.au/_accessed 18 November 2017. See also Ahmed, Pervaiz K., Ann Y. E. Loh and Mohamed Zairi, 'Cultures for continuous improvement and learning' (1999) 10(4-5) Total Quality Management 426.

${ }^{x x}$ This is also stakeholder feedback as a required KPI in the Victorian Common Funding Agreement for this project.

xxi This is also stakeholder feedback as a required KPI in the Victorian Common Funding Agreement for this project.

xxii Under a limited license to Consumer Action with Intellectual Property for the approach, tools, questions being vested in Dr Liz Curran.
} 
xxiii Curran L, 'Legal Review: Not all in the Statistics' Law Institute Journal, July 2013, 36 - 39 and Curran L' 'We Can See there's Light at the End of the Tunnel Now': Demonstrating and Ensuring Quality Service to Clients, Legal Aid ACT, (Canberra, Legal Aid ACT) (2012). http://www.legalaidact.org.au/pdf/ Light_at_the_end_of_the_Tunnel_Legal_Aid_Services_Quality_and_Outcomes.pdf xxiv Curran L, A Research and Evaluation Report for the Bendigo Health-Justice Partnership: A Partnership between Loddon Campaspe Community Legal Centre and Bendigo Community Health Services, October 2016 By Dr Liz Curran, Australian National University 'I Sleep Better at Night'. (Interview with Client) Published 22 November 2017 (October 31, 2016). Available at SSRN: https://ssrn.com/abstract=;.

${ }^{x \times v}$ For details of the 2017 data see Curran L (2017) 'First Research and Evaluation Report - Phase One Consumer Action Law Centre Project: 'Responding Effectively to Family Violence Dimensions of Debt and Credit through Secondary Consultations \& Training with Community Professional' https://workers.consumeraction.org.au/wp-content/uploads/sites/12/2017/12/Final-CALC-FV-ResearchEvaluation-Report-Phase-One-29-November-2017.pdf

xxvi Robinson, M \& Cottrell, D (2005), 'Health professionals in multi-disciplinary and multi-agency teams: Changing professional practice', Journal of Interprofessional Care, vol. 19, no. 6, pp. 547-60, doi: 10.1080/13561820500396960; Triado T, White J and Alison Brown A, Community Health Quality Health Improvement Initiatives (2013) Department of Health

<http://www.healthcaregovernance.org.au/docs/forum-1-quality-in-vic.pdf>; see also Healthy Living Network, Healthy Communities Initiative Quality Framework Guide (2012) Australian Government Department of Health and Ageing http://www.healthylivingnetwork.com.au; Healthy People 2020 Leading Health Indicators: Progress Update, available at: < https://www.healthypeople.gov/sites/default/files/LHI-ProgressReportExecSum_0.pdf >; Regenstein, M (2014), 'Developing Measures for Medical-Legal Partnership', 10 April, National Center for Medical-Legal Partnership, Milken Institute of Public Health, The George Washington University (PDF provided to the author in April 2014).

xxvii Dow AW, Zhu X, Sewell D, Banas CA, Mishra V \& Tu S (2017) 'Teamwork on the rocks: Rethinking interprofessional practice as networking', 31(6) Journal of Interprofessional Care, 677-678. DOI:

10.1080/13561820.2017.1344048; Xyrichis A and Lowton K (2007) 'What Fosters or Prevents Interprofessional Teamworking in Primary and Community Care? A Literature Review' Int J Nurs Stud 45 (1), 140-153. 2007 Mar 26; M Robinson M, Cottrell D (2005) Health professionals in multi-disciplinary and multi-agency teams: changing professional practice. Journal of Inter-professional Care 19(6), 547-560; Harris M, Advocat J, Crabtree B, Levesque J, Miller W, Gunn J, Hogg W, Scott C, Chase S, Halma L, and Russell G, IInter-professional teamwork innovations for primary health care practices and practitioners: evidence from a comparison of reform in three countries' (2016) $9 \mathrm{~J}$ Multidiscip. Healthc, 35-46, https://www.ncbi.nlm.nih.gov/pmc/articles/PMC4743635/

xxviii Curran L and Taylor-Barnett P (2019) 'Evaluating projects in multifaceted and marginalised communities: The need for mixed approaches, Evaluation Journal of Australasia Volume: 19 Issue: 1, pp: 22-38. https://journals.sagepub.com/doi/abs/10.1177/1035719X19832688; Currie A, Legal Secondary Consultations: how Legal Aid Can Support Communities and Expand Justice, (2018) https://www.cfcjfcjc.org/sites/default/files/docs/Legal\%20Secondary\%20Consultation\%20-

\%20How\%20Legal\%20Aid\%20Can\%20Support\%20Communities\%20and\%20Expand\%20Access\%20to\%20Justic e\%20by\%20Ab\%20Currie.pdf; Curran L 'Lawyer Secondary Consultations: improving access to justice and human rights: reaching clients otherwise excluded through professional support in a multi-disciplinary practice' 8(1) Journal of Social Inclusion (2017) https://josi.journals.griffith.edu.au/index.php/inclusion/article/view/8; Sanderson K, Edwards L, Williams J, Consumer Action Law Centre and Curran L, Australian National University, School of Legal Practice, 'Second Evaluation Report of Consumer Action Law Centre's Worker Advice Service -A Legal Secondary Consultation Service to Community sector professionals: One year on' 18 October 2017, https://workers.consumeraction.org.au/wp-content/uploads/sites/12/2017/11/171018-Evaluation-ReportWorker-Advice-Service-final.pdf; Ball S, Wong C (Victorian Legal Service Board (LSB)) \& Curran L, Facilitator and Adviser for Health Justice Partnerships for LSB, 'Health Justice Partnerships Development Report', 2016 http://www.Isbc.vic.gov.au/documents/Report-Health_Justice_Partnership_Development-2016.PDF; Curran L, 
Willcox T \& Williams J, 'Evaluating Consumer Action's Worker Advice Service', June 2016. https://papers.ssrn.com/sol3/papers.cfm?abstract_id=2835377; Roberts, T \& Currie, J (2012), 'PBLO at SickKids: A Phase II Evaluation of the Medical-Legal Partnership between Pro Bono Law Ontario and SickKids Hospital Toronto, Final Report', Focus Consultants, Victoria, Canada, available at: http://www.probono.net/va/search/item.451249.

xxix Crocket A \& Curran L'Measuring Legal Services: A Practical methodology for measuring quality and outcomes of legal assistance services,' University of Tasmania Law Review, 32(1), 2013, 70-95; Curran L , 'Legal Review: Not all in the Statistics' Law Institute Journal, July 2013, 36 - 39 and Curran L 'We Can See there's Light at the End of the Tunnel Now': Demonstrating and Ensuring Quality Service to Clients, Legal Aid ACT, (Canberra, Legal Aid ACT) (2012). http://www.legalaidact.org.au/pdf/

xxx Giddings, J \& Robertson, M 2001, “'Informed litigants with nowhere to go”: self-help legal aid services in Australia', Alternative Law Journal, vol. 26, no. 4, pp. 184-190; Giddings, J \& Robertson, M 2002, '“Lay people, for God's sake! Surely I should be dealing with lawyers?" Towards an assessment of self-help legal services in Australia', Griffith Law Review, vol. 11, no. 2, pp. 436-464; Giddings, J \& Robertson, M 2003, 'Large scale map or the A-Z? The place of self-help services in legal aid', British Journal of Law and Society, vol. 30, no. 1, pp. 102-119; Giddings, J \& Robertson, M 2003b, 'Unbundling legal services: making sense of helping yourself', Law Society Journal, vol. 41, no. 6, pp. 52-53 and Smith R, Digital Delivery of Legal Services to People on Low Incomes, (2016) Legal Education Foundation, UK https://www.thelegaleducationfoundation.org/digital/digitalreport accessed 18 November 2017.

xxxi https://law.anu.edu.au/people/elizabeth-curran

xxxii Egle C Rural Health Education Foundation, A Guide to Facilitating Adult Learning the Rural Health Education, (2009) Foundation and the Australian Government Department of Health and Ageing

xxxiii Curran L,_Chapter - 'Enabling Marginalised Voices to Be Heard: The Challenge to Law Reform Bodies', New Directions for Law in Australia: Essays in Contemporary Law Reform, edited by Ron Levy, Molly O'Brien, Simon Rice, Pauline Ridge and Margaret Thornton, published 2017 by ANU Press, The Australian National University, Canberra, Australia, Chapter 48, $517 \quad$ - $\quad 527 . \quad$ dx.doi.org/10.22459/NDLA.09.2017.4 https://pdfs.semanticscholar.org/ea79/af1abc0716614befde0e6bb86f54932a6835.pdf

xxxiv Curran L Making the legal system more responsive to community: A report on the impact of Victorian Community Legal Centre law reform initiatives. Research and Report (2007) funded by the Reichstein Foundation ISBN $978-0-646-47603-2$.

http://trove.nla.gov.au/work/5544060?selectedversion=NBD41897818; Curran L, 'Solving Legal Problems: A strategic approach', March 2013, Footscray Community legal Service and Consumer Action Law Centre, http://consumeraction.org.au/wp-content/uploads/2013/03/ANU-VersionFinal-Report-Solving-Legalproblems-Curran-CALC-13-March-2013.pdf

xxxv Curran L, 'Enabling Marginalised Voices to Be Heard: The Challenge to Law Reform Bodies', New Directions for Law in Australia: Essays in Contemporary Law Reform, edited by Ron Levy, Molly O’Brien, Simon Rice, Pauline Ridge and Margaret Thornton,2017, ANU Press, The Australian National University, Canberra, Australia, Chapter 48, 517 - 527. Curran L, 'Solving Legal Problems: A strategic approach', March, 2013, Footscray Community legal Service and Consumer Action Law Centre, http://consumeraction.org.au/wpcontent/uploads/2013/03/ANU-VersionFinal-Report-Solving-Legal-problems-Curran-CALC-13-March-2013.pdf ; Curran L Making the legal system more responsive to community: A report on the impact of Victorian Community Legal Centre law reform initiatives. Research and Report (2007), Reichstein Foundation, http://trove.nla.gov.au/work/5544060?selectedversion=NBD41897818.

xxxvi The Report of the Royal Commission into Family Violence (Victoria) Summary and Recommendations, 5. http://www.rcfv.com.au/Report-Recommendations.

xxxvii This is the term commonly used in Canada to describe the trusted relationship between a client and their health, allied health or social worker than develops and is key to building bridges between complex clients and other professionals to build 'borrowed trust'. See Ab Currie A (2018) 'Legal Secondary Consultations: How 
Legal Aid Can Support Communities and Expand Access to Justice' Report Halton Law Clinic, Ontario, Canada. https://www.haltonlegal.ca/docs/LSC Report-final.pdf. 